\title{
COMBATING CORRUPTION IN INTERNATIONAL BUSINESS TRANSACTIONS*
}

\author{
Marco Celentani ${ }^{\dagger}$ Juan-José Ganuza ${ }^{\ddagger}$ And José-Luis Peydró ${ }^{\S}$
}

OCTOBER 2003

\begin{abstract}
International business transactions pose the problem of deterring bribing of public officials by foreign firms. We first analyze a convention styled after the OECD's "Convention on Combating Bribery of Foreign Public Officials in International Business Transactions" that requires signatory countries to proceed against firms that have bribed public officials of any foreign country. We then study the case in which the convention requires signatory countries to proceed against firms that have bribed public officials of signatory countries only. We argue that the second type of convention is more likely to ensure enforcement of penalties.
\end{abstract}

KEYWORDS: International corruption, OECD Convention

JEL classification numbers: D72, F23, K42.

${ }^{*}$ Marco Celentani gratefully acknowledges the financial support of Fundación BBVA, Fundación Ramón Areces, and MCYT (Spain) under project BEC2002-03715. Juan-José Ganuza gratefully acknowledges the financial support of MCYT (Spain) under project BEC2000-1026 and fellowship Ramón y Cajal. We thank Jorge Padilla, Rafael Repullo, Lambra Saínz, Javier Suarez, Tim Van Zandt and Seminar participants at CEMFI, INSEAD, and Simposio de Análisis Económico (Seville, 2003).

${ }^{\dagger}$ Department of Economics, Universidad Carlos III, Getafe (Madrid) 28903, Spain; fax +34-91-624 9875; marco.celentani@uc3m.es.

${ }^{\ddagger}$ Department of Economics, Universitat Pompeu Fabra, Carrer Ramón Trías Fargas, 23-27, 08005, Barcelona, Spain; fax: +34-93-542 1746; juanjo.ganuza@econ.upf.es.

${ }^{\S}$ Department of Finance, INSEAD, Boulevard de Constance, 77305, Fontainebleau, France; fax: +33 (0) 16072 40 45, jose.peydro@insead.edu. 


\section{INTRODUCTION}

Market participation of foreign firms is commonly believed to promote competition and efficiency. But international business transactions pose the problem of effectively deterring bribing of public officials by foreign firms. Many corrupt transactions involve companies that are incorporated in different countries and that take advantage of the disparities among national legal systems and of the limited ability to enforce national judicial rulings with foreign nationals and companies. Most countries do not prosecute domestic firms or their executives when they are found to have bribed foreign public officials. Some countries regard bribes paid to foreign officials as necessary business expenses to produce taxable income and therefore consider them tax deductible.

In the past few years several international organizations, including the WTO, the UN, the Council of Europe, and the OECD, have recognized the importance of this reality and have started projects that aim to provide an effective supranational framework to fight corruption. As an example, the OECD's "Convention on Combating Bribery of Foreign Public Officials in International Business Transactions" is an attempt to induce individual countries to regard corruption of foreign public official in the same terms as corruption of domestic public officials. A country that signs the Convention commits to prosecuting its firms found to have bribed foreign public officials as if they had bribed a local public official.

The OECD Convention entered into force in February 1999. For the Convention to enter into force it was required that it be approved by 5 of the 10 countries with the largest shares of OECD exports, representing at least $60 \%$ of the combined total exports of those 10 countries. By september 2001, 28 OECD member countries and 5 non-member countries had approved the Convention. Under OECD auspices, a process of multilateral surveillance began in April 1999, with the purpose of monitoring compliance with the Convention and assessing the steps taken by countries to implement it in national law. ${ }^{1}$

After initial euphoria caused by the OECD Convention's generalized approval and public praise, mounting evidence of lack of enforcement has generated a more dismal view in the financial and business press. "When OECD member countries signed a convention in 1997 outlawing bribery by multinational companies of officials abroad, it was regarded as a milestone in the global fight against corruption. But five years later the convention is in crisis. It has produced no prosecutions [...] In a Transparency International Survey of senior managers in emerging market economies, conducted by Gallup International between December 2001 and March 2002, only one in five respondents knew something about the convention." "[T] 2 he London-based Control Risk Group [...] found that only 56 percent of British companies, 38 percent of German and 30 of Dutch companies were familiar with the convention. Moreover, new laws have not resulted in any convictions." 3

This paper is an attempt to provide an initial analysis of corruption in international business transactions by studying the extent to which different international arrangements are likely to make anti-corruption legislations enforced beyond national borders. In particular, we ask how likely the OECD Convention is to succeed in its goal and whether a different institutional arrangement may lead to superior results.

We consider a multi-country model of procurement. Each country procures one unit of a good and the procurement process is managed by a public official. Firms active in a country may attempt to bribe the public official in order to be awarded the procurement contract. Individual

\footnotetext{
${ }^{1}$ Information about the OECD Convention may be obtained from http://www.oecd.org.

${ }^{2}$ Eigen (2002), page 6. Peter Eigen is the Chairman of Transaparency International, an NGO dedicated to the fight against corruption.

${ }^{3}$ Burns (2002), page 12. Similar opinions are also found in The Economist (2002).
} 
countries simultaneously set the penalties that are imposed on domestic firms that operate in the same country and on domestic firms operating abroad. After that, each country sets the monitoring intensity that determines the probability with which a corrupt transaction is discovered. When a corrupt transaction is discovered, a penalty is imposed on the bribing firm. When the firm discovered to have bribed the public official is a local firm, the government has the ability to enforce the penalty . But if the firm is foreign, the penalty is not enforced unless the firm's home country "cooperates" with the judicial system of the country where the illegal transaction took place. After countries have publicly set penalties and monitoring technologies, firms offer bribes in a probabilistic auction. As a result, the contract available in any one country is awarded to one firm that operates in that country with a probability that depends on the bribe it offered. In this situation, we find, unsurprisingly, that because enforcing penalties is costly, it is a dominant strategy for each individual country not to impose any penalties on domestic firms bribing foreign public officials.

We then examine whether international cooperation is more likely to arise when a convention similar to the OECD Convention is proposed and when individual countries have to simultaneously decide whether to adhere to the Convention before setting penalties and monitoring probabilities. We make use of a simple model in which countries that sign the Convention have the ability of committing to enforce it. The discussion of the recent evidence on the OECD Convention clarifies that a country that signs a convention may in the end choose not to enforce it. This in turn implies that the meaningful decision is not whether to sign the Convention or not, but rather whether to enforce it or not. Our paper is concerned with the second decision, but for ease of exposition, we make reference to a situation in which countries decide to sign the convention but have the ability to commit to enforcing it.

We find that a convention styled after the OECD Convention may generate some degree of international cooperation and that multiple and Pareto ranked equilibria exist. Our analysis centers in particular on the impact of the clause that requires a minimum number of signatory countries for the Convention to enter into force. We show that this minimum threshold may be beneficial, because it can rule out high corruption equilibria, but may also be detrimental because, if it is set too high, it may leave only one equilibrium in which no country signs the convention.

We finally consider an alternative convention that stipulates that signatory countries commit to enforcing penalties on domestic firms which are found to have bribed the public official of signatory countries only. We find that this kind of convention accomplishes two objectives. First, it provides additional incentives to sign the convention because the benefits of the convention are enjoyed only by the countries that sign it. Second, it reduces the enforcement costs that derive from signing the convention when few countries sign it. This reduces the incentives not to sign the convention when few countries are expected to sign and therefore makes the emergence of equilibria with a reduced number of signatory countries less likely. We argue that these effects make the reciprocal convention a more appealing institutional framework than the OECD convention.

The growing international nature of corruption is an aspect that has largely been ignored by the economic profession until recently. Davis (2002) analyzes the incentives of payor countries (i.e., countries where bribing companies are incorporated) to unilaterally proceed against their firms found to have bribed foreign public officials. Because of its focus on corruption in procurement, our paper is related to the existing literature on corruption in procurement and in particular to the works on the optimal response of procurement mechanisms to corruption, such as Laffont and Tirole (1991), Laffont and N'Guessan (1999) or Celentani and Ganuza (2002). 


\section{The Model}

Consider $N$ sovereign countries and $N^{2}$ firms. Firm $(i, j)$ is incorporated in country $i$ and operates in country $j, i=1, \ldots, N, j=1, \ldots, N$. This means that $N$ firms operate in each country, one locally incorporated and $N-1$ foreign, and that each country has $N$ firms, one that operates in the country and $N-1$ abroad. ${ }^{4}$ We choose to consider the case of $N$ countries, because the case with 2 countries is a special one in which an important effect that will be discussed later is absent. The government of each country has to procure a good that can be produced at different quality levels. For simplicity, we assume there are only two levels of quality, low and high. When quality is low, the government's valuation of the good is $V$ and when it is high it is $\bar{V}>V$. Given that the government of country $i$ makes decisions on behalf of country $i$, in the rest of the paper we will use the two terms interchangeably.

The good to be procured by each government is purchased from any one of the $N$ firms that operate in the country. All firms are commonly known to have the same production costs. We denote by $\underline{K}$ and $\bar{K}$ the cost of producing low and high quality, respectively, with $0 \leq \underline{K}<\bar{K}$. For the sake of simplicity, in the rest of the paper we assume that it is profitable for governments to procure the good at the high quality level in all equilibria. Notice that a necessary condition for this to happen is that it is efficient to procure high quality, i.e., $\bar{V}-\underline{V}>\bar{K}-\underline{K}$.

Each government delegates the execution of the procurement process to a public official who is able to verify that the good is of high quality prior to making the payment to the supplying firm. Firms are risk-neutral and maximize expected profits. Given that all firms are commonly known to have the same cost, we assume that the public official randomly selects a firm operating in the country and awards it a procurement contract that requires high quality and that promises a payment of $\bar{K}$ if the high quality good is supplied.

Any firm can bribe the public official to be awarded the project and be illegally allowed to supply low quality, an event we refer to as corruption. We assume that a corrupt transaction is the result of the following probabilistic auction. Each firm in a given country sets a nonnegative bribe. If firm $(i, j)$ (incorporated in country $i$ and operating in country $j$ ) sets bribe $\beta_{i j} \geq 0$ it will win the auction (it will succeed in corrupting the public official of country $j$ ) with probability

$$
\gamma_{i j}=\frac{\beta_{i j}}{B}
$$

where $B>0$ is an exogenous parameter that measures public officials' propensity to corruption. ${ }^{5}$ A firm $(i, j)$ is required to pay the bribe it offered, $\beta_{i j}$, only if it wins the auction (only if it succeeds in corrupting the public official of country $j$ ), i.e., only with probability $\beta_{i j} / B$. Under this probabilistic auction a firm that bids a higher bribe has a higher probability of corrupting the public official, but this probability is less than 1. Our way of modeling corruption is similar to the way in which rent seeking is often modeled, but two differences exist. First, we assume that the bribe bid by each individual firm is a promise of payment if it is awarded the contract and that no outlay is required of firms that have not been awarded the contract. This contrasts with the literature on rent seeking that assumes that rent seekers' expenditures are unconditional, so that also losing rent seekers bear the cost of participating in the contest. Second, we assume

\footnotetext{
${ }^{4}$ To retain symmetry we want to focus on a situation in which each country has a firm that is active in each other country. An alternative, equivalent formulation is one in which each country only has one (multinational) firm that operates in all countries.

${ }^{5} B$ may include factors such as the penalty for the public official or his opportunity cost for losing his job. For the sake of simplicity we assume that $B$ is the same for all countries, but our results can be generalized to the case in which the public officials of different countries have different propensities to be corrupt.
} 
that the probability of corruption is less than 1 and we are especially interested in determining what causes this probability to be higher or lower. By contrast, the literature on rent seeking normally assumes that the rent is assigned with probability 1 and that an individual bidder's expenditure only has an impact on its own probability of being awarded the rent, but not on the overall probability of the rent being assigned.

For the sake of simplicity, in what follows we will assume that all equilibria are interior, so that in particular

$$
\begin{aligned}
\beta_{i j} & \geq 0 \text { for all }(i, j) \\
\sum_{i=1}^{N} \frac{\beta_{i j}}{B} & <\bar{\beta}<1 \text { for all } j .
\end{aligned}
$$

Notice that (3) implies that in all equilibria there is probability at least $1-\bar{\beta}>0$ that no corruption takes place. This is important, because the assumption that the government requires high quality is justified only if this probability is positive and sufficiently high.

When firm $(i, j)$ bribes the public official of country $j$, they are discovered with probability $\mu_{j} \in[0,1]$ which is determined by the government of country $j$. We assume that if firm $(i, j)$ is found to have bribed the public official of country $j$, it receives a nonmonetary penalty $\pi_{i j}$ which is determined by the government of country $i$, the country where the firm is incorporated. This assumption is meant to recognize that each country has very limited ability to enforce penalties on firms incorporated in foreign countries, unless these foreign countries cooperate. We assume that only two possible levels for penalties exist, $\pi_{i j} \in\{0, \bar{\pi}\}$ with $\pi_{i j}=\bar{\pi}>0$ meaning that firm $(i, j)$ is penalized by country $i$ and $\pi_{i j}=0$ meaning that firm $(i, j)$ is not penalized by country $i$. Our description should be regarded as a stylized representation of a situation in which enforcement of penalties against foreign firms and their executives is less effective than enforcement of a penalty against a domestic firm and its executives. The assumption that without cooperation of the country where the firm is incorporated the penalty is 0 is without loss of generality. Our qualitative results would be the same with nonzero but lower effective deterrence for foreign firm.

We assume that if a country chooses monitoring probability $\mu$, it bears cost

$$
\mathcal{M C}_{i}(\mu)=\frac{M}{2} \mu^{2}
$$

where $M>0$ is an exogenous parameter. We also assume that if country $i$ prosecutes firm $(i, j)$ (when this is found to have bribed the public official of country $j$ ) it bears a cost equal to $P>0$.

Let

$$
\begin{aligned}
\mu & =\left(\mu_{i}\right)_{i=1}^{N} \\
\gamma & =\left(\left(\gamma_{i j}\right)_{j=1}^{N}\right)_{i=1}^{N} \\
\pi & =\left(\left(\pi_{i j}\right)_{j=1}^{N}\right)_{i=1}^{N}
\end{aligned}
$$

and let

$$
\gamma_{i}=\sum_{j=1}^{N} \gamma_{i j}
$$

denote the probability of corruption in country $i$.

The government of country $i$ is risk neutral and has preferences represented by the following utility function 


$$
\mathcal{G}_{i}(\mu, \pi, \gamma)=\left(1-\gamma_{i}\right)(\bar{V}-\bar{K})+\gamma_{i}(\underline{V}-\bar{K})-\frac{M}{2} \mu_{i}^{2}-\sum_{j=1}^{N} \gamma_{i j} \mu_{j} \frac{\pi_{i j}}{\bar{\pi}} P .
$$

The first two terms refer to the expected net utility of procuring the good. With probability $1-\gamma_{i}$ there is no corruption. In this case the good is of high quality, it is worth $\bar{V}$ to the government, and the payment to the supplier is $\bar{K}$. With probability $\gamma_{i}$ there is corruption. In this case the good is of low quality, it is worth $V$ to the government and the payment to the supplier is $\bar{K}$. The third term represents the cost to government $i$ of setting a monitoring probability equal to $\mu_{i}$. The last term represents the cost to the government of country $i$ of prosecuting domestic firms that operate in the country or abroad. The cost of prosecuting firm $(i, j)$ (i.e., setting $\pi_{i j}=\bar{\pi}$ ) is $P$ multiplied by the probability that firm $(i, j)$ is involved in a corrupt transaction which is uncovered in country $j, \gamma_{i j} \mu_{j}$. Notice that we ignore the cost of prosecuting (successfully or unsuccessfully) foreign firms that operate in the country, because these costs are likely to be considerable but are inessential for the purposes of the paper. ${ }^{6}$

In the following we will find it useful to view the payoffs to the government of any one country as the benefits of procurement, $\mathcal{B P}_{i}(\gamma)$,

$$
\mathcal{B P}_{i}(\gamma)=\left(1-\gamma_{i}\right)(\bar{V}-\bar{K})+\gamma_{i}(\underline{V}-\bar{K})
$$

minus the monitoring cost, $\mathcal{M C}_{i}(\mu, \pi, \gamma)$, defined above, minus the enforcement cost, $\mathcal{E C}_{i}(\mu, \pi, \gamma)$,

$$
\mathcal{E C}_{i}(\mu, \pi, \gamma)=\sum_{j=1}^{N} \gamma_{i j} \mu_{j} \frac{\pi_{i j}}{\bar{\pi}} P
$$

Summarizing we can express the utility function of the government of country $i$ as:

$$
\mathcal{G}_{i}(\mu, \pi, \gamma)=\mathcal{B P}_{i}(\mu, \pi, \gamma)-\mathcal{M C}_{i}(\mu, \pi, \gamma)-\mathcal{E C}_{i}(\mu, \pi, \gamma)
$$

The preferences of firm $(i, j)$ are represented by the following utility function

$$
\mathcal{F}_{i j}\left(\beta_{i j}, \mu_{j}, \pi_{i j}\right)=\frac{\beta_{i j}}{B}\left[(\bar{K}-\underline{K})-\beta_{i j}-\mu_{j} \pi_{i j}\right]
$$

In words, if firm $(i, j)$ is not involved in a corrupt transaction, it makes zero profit. If it is, an event which happens with probability $\gamma_{i j}=\frac{\beta_{i j}}{B}$, it makes an extra profit equal to $(\bar{K}-\underline{K})$, it pays out bribe $\beta_{i j}$ to the public official of country $j$, and it suffers an expected penalty equal to $\mu_{j} \pi_{i j}$

We summarize the extensive form of the game through the following time sequence:

- Stage 1 (penalties): The governments of all countries announce contests to procure high quality goods and publicly set penalties for corruption. Government $i$ sets $\left(\pi_{i j}\right)_{j=1}^{N}$.

- Stage 2 (monitoring probabilities): The governments of all countries observe $\left(\left(\pi_{i j}\right)_{j=1}^{N}\right)_{i=1}^{N}$ and choose monitoring probabilities. Government $i$ sets $\mu_{i}$.

\footnotetext{
${ }^{6}$ Taking these costs into account would recognize an additional source of externality. When a country prosecutes its firms abroad, it reduces the probability that they are involved in corrupt transactions and therefore benefits foreign countries by reducing their expected prosecution costs.
} 
- Stage 3 (bribe bidding): Firms $(i, j), i=1, \ldots, N, j=1, \ldots, N$, observe $\left(\mu_{i},\left(\pi_{i j}\right)_{j=1}^{N}\right)_{i=1}^{N}$ and choose $\beta_{i j} \geq 0$.

- Stage 4 (outcomes and payoffs): In each country $i=1, \ldots, N$ the public official is bribed by firm $(i, j)$ with probability $\gamma_{i j}=\frac{\beta_{i j}}{B}, j=1, \ldots, N$. In this case firm $(i, j)$ is awarded the procurement project, produces a low quality good, is reimbursed for the high quality good, and pays out bribe $\beta_{i j}$ to the public official. With probability $\mu_{i}$ the corrupt agreement is uncovered and penalty $\pi_{i j}$ is imposed on the firm.

With probability $1-\gamma_{i}$ the public official of country $i$ is not bribed by any firm. In this case, the public official randomly awards the project to any firm $(i, j), j=1, \ldots, N$. Firm $(i, j)$ produces a high quality good and is reimbursed its cost.

We denote by $\Gamma$ the game defined by the previous extensive form. For the sake of simplicity in the following we will focus on parameter constellations such that SPNE outcomes are all interior, i.e., $\mu_{i} \in(0,1), \gamma_{i j} \in(0,1), \gamma_{i} \in(0,1)$, for all $i$ and all $j$. Notice that this is always the case provided that $B$ is sufficiently high and that $P$ is not too high,

$$
P<\frac{\bar{V}-\underline{V}}{\bar{K}-\underline{K}} \bar{\pi}
$$

We now want to justify the way in which we model corruption and in particular the choice of endogenizing corruption probabilities through the probabilistic auction described above. First, note that our main goal is to study how different deterrence mechanisms endow private parties with different incentives to engage in corrupt transactions. Recall that the probabilistic auction we propose implies that firms which offer higher bribes have a higher probability of corrupting the public official, but that any firm that bids a positive bribe has a positive probability of corrupting the public official. Given that firms with higher expected gains from corruption find it optimal to offer higher bribes, the probabilistic auction

1. Takes into account that firms with higher incentives to engage in corrupt transactions are more likely to corrupt a public official.

2. Recognizes that any firm with a positive expected gain from corruption has a positive probability of succeeding in corrupting the public official.

Property 1 seems uncontroversial in that it conveys the idea that corruptors' willingness to pay is important. Property 2 states that the public official may strike a deal with a firm that is not the one willing to pay the highest bribe. We believe that property 2 is appealing for the following reason. Corrupt arrangements are illegal and therefore face significant and varying transaction costs arising from asymmetric information and the absence of legal commitments. This may ultimately lead to a corrupt transaction with a firm different from the one that can generate the highest surplus and is therefore willing to pay the highest bribe. For example, existing communication networks and established reputations may reduce transaction costs with some selected firms and may make an agreement with these firms more likely, regardless of their expected gains from corruption.

The probabilistic auction should be regarded as a reduced form that describes how different incentives to engage in corrupt transactions translate into corruption probabilities. We believe that resorting to a reduced form model is appropriate, because corruption can be organized in a 
wide variety of different ways, and any detailed description of the process that leads to a corrupt agreement is bound to be incomplete and may lead to unreasonable predictions. ${ }^{7}$

Before concluding it is also important to underline that our probabilistic auction implies that the probability of any one firm succeeding in bribing the public official depends only on the bribe it promises and on $B$, the propensity of the public official to become corrupt (see equation (1)). In other words the probability of a firm succeeding in bribing the public official is independent of the bribes which are promised by the other firms. ${ }^{8}$ This simplifies the analysis because firms have dominant strategies in the bribe setting game of stage 3 . But it is also useful to underline that the results of the paper would be unchanged in a more general environment in which the probability of a firm bribing the public official also depends on the bribes of competing firms. For example, we have verified that all our results hold when

$$
\gamma_{i j}=\frac{\beta_{i j}+l\left(\beta_{i j}-\frac{1}{N} \sum_{z=1}^{N} \beta_{z j}\right)}{B}
$$

with $l \in[0,1)$ and $\gamma_{i j} \in[0,1]$; notice that $(1)$ is a special case of $(6)$ in which $l=0$. With this specification, which is reminiscent of models of yardstick competition, if firm $(i, j)$ chooses a bribe that gives it a positive probability of succeeding in bribing the public official of country $j$, this probability is increasing in its own bribe and increasing in the difference between its own bribe and the average bribe. This implies that the probability of succeeding in bribing the public official is decreasing in the bribes bid by competing firms. ${ }^{9}$

\section{The Basic Game: Free Riding}

This section studies subgame perfect Nash equilibria (SPNE) of $\Gamma$. We start by analyzing individual firms' play at stage 3 .

LEMMA 1 In a SPNE of $\Gamma$

$$
\beta_{i j}=\frac{1}{2}\left[(\bar{K}-\underline{K})-\mu_{j} \pi_{i j}\right], i=1, \ldots, N, j=1, \ldots, N
$$

Proof. Appendix.

Lemma 1 states that each firm $(i, j)$ bids a bribe that is proportional to the value of the corrupt agreement minus its expected penalty. From Lemma 1, the probability that the firm $(i, j)$ reaches a corrupt agreement with the public official of country $j$ is

$$
\gamma_{i j}=\frac{1}{2 B}\left[(\bar{K}-\underline{K})-\mu_{j} \pi_{i j}\right]
$$

and the probability of corruption taking place in country $j$ is

$$
\gamma_{j}=\frac{1}{2 B}\left[N(\bar{K}-\underline{K})-\mu_{j} \sum_{i=1}^{N} \pi_{i j}\right]
$$

\footnotetext{
${ }^{7}$ As mentioned above, the literature on rent seeking also views the allocation of rents as deriving from contest success functions that have desirable properties such as that the probability of a rent seeker being assigned the rent is higher when he expends more resources in the contest.

${ }^{8}$ We thank an anonymous referee for pointing out the importance of justifying this assumption.

${ }^{9}$ Appendix B analyzes the bribing game in which the probability of succeeding in bribing the public official is as in $(6)$.
} 
We now turn to the monitoring probabilities set by governments in stage 2 . Let

$$
\pi_{F i}=\sum_{j \neq i} \pi_{j i}
$$

denote the sum of penalties imposed by foreign governments on the respective foreign firms operating in country $i$.

LEMMa 2 In a SPNE of $\Gamma$

$$
\mu_{i}=\frac{(\bar{V}-\underline{V})\left(\pi_{i i}+\pi_{F i}\right)-\frac{\pi_{i i}}{\pi} P(\bar{K}-\underline{K})}{2\left(M B-\frac{\pi_{i i}}{\pi} P \pi_{i i}\right)} i=1, \ldots, N
$$

Proof. Appendix.

Lemma 2 shows that in stage 2 , the monitoring intensity chosen by the government of country $i$ is increasing in $\bar{V}-\underline{V}$, the value of deterring corruption, increasing in $\pi_{F i}$ the sum of the penalties faced by the foreign firms operating in the country, and decreasing in $\bar{K}-\underline{K}$, the value of a corrupt agreement to the corrupt parties.

The following Proposition characterizes the path of the SPNE of $\Gamma$.

Proposition 1 In the path of the unique SPNE of $\Gamma$, for $i=1, \ldots, N$

$$
\begin{aligned}
\pi_{i j}^{*} & = \begin{cases}\bar{\pi} & \text { if } j=i \\
0 & \text { if } j \neq i\end{cases} \\
\mu_{i}^{*} & =\frac{(\bar{V}-\underline{V}) \bar{\pi}-(\bar{K}-\underline{K}) P}{2(B M-\bar{\pi} P)} \\
\beta_{i j}^{*} & =\frac{1}{2}\left[(\bar{K}-\underline{K})-\mu_{j}^{*} \pi_{i j}^{*}\right] \\
\gamma_{i j}^{*} & = \begin{cases}\frac{1}{2 B}\left[(\bar{K}-\underline{K})-\mu_{j}^{*} \bar{\pi}\right] & \text { if } j=i \\
\frac{1}{2 B}(\bar{K}-\underline{K}) & \text { if } j \neq i\end{cases} \\
\gamma_{j}^{*} & =\frac{1}{2 B}\left[N(\bar{K}-\underline{K})-\mu_{j}^{*} \bar{\pi}\right]
\end{aligned}
$$

Proof. Appendix.

Proposition 1 states that in a SPNE of $\Gamma$ the government of each country $i$ sets a positive penalty on firm $(i, i)$, the domestically incorporated firm that operates in the country, $\pi_{i i}^{*}=\bar{\pi}>0$. The government of country $i$ finds this optimal because a positive penalty on firm $(i, i)$ decreases the probability that the firm bribes the public official and therefore decreases the total probability that the local public official is involved in a corrupt transaction. On the other hand, given that imposing a penalty on firm $(i, j), j \neq i$, is costly to the government of country $i$ but beneficial only for country $j$, no government imposes penalties on domestically incorporated firms that operate abroad, i.e., for all $i=1, \ldots, N, \pi_{i j}=0, \forall j \neq i$. Given that a positive penalty on firm $(i, i)$ makes monitoring valuable, in a SPNE the government of each country $i$ sets a positive monitoring probability that is such that the marginal value of deterring corruption of firm $(i, i)$ is equal to the marginal cost of monitoring.

From Proposition 1, the probability that a public official is bribed by an arbitrary foreign firm is higher than the probability that he is bribed by the domestic firm, $\gamma_{i j}>\gamma_{i i}$, because foreign firms face lower expected penalties and therefore find it optimal to offer higher bribes. This implies that in the stylized setting described in this paper an easy if partial remedy against 
corruption would be to require that the procurement contract always be awarded to the domestic firm. This result is an artificial consequence of some simplifying assumptions we make and in particular:

1. Firms do not have private information about their costs or other possibly relevant parameters, such as their quality. This implies that competition plays no role in achieving efficiency and in reducing the expected procurement cost.

2. A bribe of a given amount is equally likely to succeed in bribing the public official regardless of whether it is offered by a domestic or a foreign firm. This implies that we do not recognize that local firms are normally more effective in establishing the connections with public officials and we therefore underestimate the probability that they are involved in a corrupt transaction. ${ }^{10}$

In other words, we share the common views that participation of foreign firms promotes competition and leads to efficiency gains and that, ceteris paribus, domestic firms are more likely to succeed in bribing the public official. For these reasons we believe that it is desirable to allow foreign bidders to participate in competitive procurement mechanisms. But to retain the analysis tractable, rather than proposing a model in which it is optimal to allow foreign firms to participate, we simply assume that they are allowed, even if they are subject to a less effective penalty scheme. ${ }^{11}$ The focus of our paper is on how to rein in foreign firms' propensities to bribe public officials.

\section{The Impact of Conventions on International Bribery}

The previous section serves to make the point that it is costly for the government of country $i$ to impose penalties on its firms that operate abroad and that the beneficial effects deriving from corruption deterrence are enjoyed only by foreign countries. As a consequence no such penalties are imposed in equilibrium.

This section studies international conventions designed to deter international corruption by requiring countries to impose penalties on their firms operating abroad. Before turning to this analysis we first wish to study the consequences of setting penalties on firms operating abroad.

COROLlary 1 Consider a subgame of $\Gamma$ starting at stage 2. In a SPNE of this subgame

$$
\begin{aligned}
& \frac{\partial \mu_{i}}{\partial \pi_{F i}}>0 \\
& \frac{\partial \gamma_{i}}{\partial \pi_{F i}}<0 \\
& \frac{\partial \mathcal{G}_{i}}{\partial \pi_{F i}}>0
\end{aligned}
$$

Proof. Appendix.

Corollary 1 states that when $\pi_{F i}$, the sum of the penalties faced by foreign firms in country $i$, is higher, the government of country $i$ finds it optimal to increase the monitoring intensity,

\footnotetext{
${ }^{10}$ This assumption has been made, among others, by Laffont and Tirole (1991) who provide several examples of favoritism towards domestic firms in international trade.

${ }^{11}$ For an analysis of bribing and procurement in asymmetric information settings, see Laffont and Tirole (1991) and Celentani and Ganuza (2002).
} 
because the larger penalties increase marginal deterrence and therefore make monitoring more valuable at the margin. Corollary 1 also states that an increase in $\pi_{F i}$ leads to a reduction in corruption in country $i$. This deterrence arises for two reasons. First, increasing penalties has a direct effect because it makes bribing more costly in expected terms. Second, larger penalties lead to higher monitoring intensities, and this reinforces the increase in the expected penalty. Finally, Corollary 1 states that if the government of a country $j$ imposes penalties on its firm operating in country $i \neq j$ it creates positive externalities on country $i$.

In the following we introduce a class of conventions inspired by the OECD "Convention on Combating Bribery of Foreign Public Officials in International Business Transactions"

Definition 1 Convention $U(\tau), \tau=1, \ldots, N$ : If a country signs the Convention and the Convention enters into force, the country commits to imposing the same penalty on all domestically incorporated firms found to have bribed a public official regardless of the country where the public official is based. The Convention enters into force only if the number of signatory countries is greater than or equal to the threshold $\tau$.

Note that we denote this type of Convention by $U(\tau)$ to underline that the Convention is unilateral in the sense that a signatory country commits to prosecuting its firms bribing public officials of any foreign country, regardless of whether these countries reciprocate or not. As in the OECD Convention, under this kind of Convention, countries are allowed to choose their monitoring efforts, but they are required to enforce uniform penalties on domestic firms that have been found to have bribed public officials of any country. In other words, signatory countries commit to equating penalties for bribing domestic and foreign public officials. Focusing on this type of conventions implicitly recognizes that it may be very difficult to verify monitoring efforts, but that it is easier to verify whether countries enforce penalties on domestic firms that are found to have bribed foreign public officials.

In the following we will focus on the game in which individual countries, before setting penalties and monitoring probabilities, decide whether to sign a given convention $\mathcal{C}=U(\tau), \tau=1, \ldots, N$, that constrains their subsequent choices.

DeFINITION 2 Let $\Gamma(\mathcal{C})$ be the game in which the government of individual countries simultaneously decide at stage 0 whether to sign Convention $\mathcal{C}$ and then play as in $\Gamma$, with the possible restrictions that having signed Convention $C$ may entail. Preferences for all players are inherited from $\Gamma$.

Notice that in $\Gamma(\mathcal{C})$ Convention $\mathcal{C}$ is given. This means that countries cannot propose or agree on a convention different from $\mathcal{C}$, but can only decide at stage 0 whether they sign Convention $\mathcal{C}$ or not. We focus on this game because we are interested in analyzing individual countries' reactions to given conventions, rather than predicting what conventions are likely to be proposed. In other words the prime objective of this paper is a normative rather than a positive analysis.

To analyze the SPNE of $\Gamma(\mathcal{C})$ we proceed backward and start from firms' bidding strategies in stage 3. Note that in a SPNE of $\Gamma(\mathcal{C})$ the bribe offered by any one firm depends on whether a convention is in force or not only because the convention may have an impact on the penalties and the monitoring probabilities set by governments in stages 1 and 2 . In other words firms' SPNE bidding strategies in stage 3 of $\Gamma(\mathcal{C})$ are identical to the SPNE bidding strategies in $\Gamma$ and are therefore characterized by Lemma 1.

A similar argument applies to monitoring probabilities set by individual countries in stage 2 of $\Gamma(\mathcal{C})$, and SPNE monitoring probabilities are therefore still characterized by Lemma 2 . Notice 
in particular that, because by Lemma 2 a country's monitoring probability depends only on the sum of the penalties on the firms active in the country, when a convention is in force all signatory countries will choose the same monitoring probability and all nonsignatory countries will choose a higher one. To see this, notice that if $n$ countries sign Convention $U(\tau)$ and the Convention enters into force (i.e., $n \geq \tau$ ), a non-signatory country faces $n$ signatory countries, but a signatory country only $n-1$. It is important to remark that while nonsignatory countries have higher monitoring probabilities, the monitoring probability of a given country does not depend on whether the country signs the Convention or not. In other words, if a nonsignatory country decides to deviate and sign the Convention, its monitoring probability is unaffected whereas the monitoring probabilities of all other countries increase.

Under a Convention $U(\tau)$, stage 1 SPNE strategies are very easily characterized. When at least $\tau$ countries sign the Convention in stage 0 , in stage 1 signatory countries set positive penalties for all their firms, regardless of whether they operate in the home country or abroad, and each nonsignatory country sets a positive penalty only for the domestic firm that operates in the country. When less than $\tau$ countries sign the Convention at stage 0 , each country sets a positive penalty only for the domestic firm that operates in the country.

In the next Proposition we make use of the previous results and move to the characterization of SPNE strategies in stage 0. Rather than presenting the results for Conventions $U(\tau), \tau=$ $1, \ldots, N$, we focus our attention on Convention $U(N)$ in particular, because it has a special interest for our analysis. For the sake of completeness we will briefly summarize the results for Conventions $U(\tau), \tau=1, \ldots, N-1$ at the end of the present section.

Proposition 2 In $\Gamma(U(N))$ there is a unique SPNE in which all $N$ countries sign the Convention.

Proof. Appendix.

Proposition 2 clarifies that when $\tau=N$ each country becomes pivotal to the Convention entering into force. This implies that when considering a possible deviation from a profile in which all $N$ countries sign Convention $U(N)$, each country compares the situation in which all countries penalize their firms abroad with one in which none does. Given the symmetry in the model, the assumption that guarantees that each country sets a positive penalty for the domestic firm that operates in the country also ensures that the benefit deriving from a Convention undersigned by all $N$ countries is at least as large as the enforcement cost that each country has to bear for signing it. Therefore, a unilateral deviation from the profile in which all $N$ countries sign the Convention is not profitable.

An implication of Proposition 2 is that a unilateral Convention that enters into force only if all $N$ countries sign it, will lead to all countries signing the Convention and therefore to the Convention entering into force. In this sense Proposition 2 suggests that there is an easy solution to the problem of international corruption. In the rest of this section we argue that this interpretation is overly optimistic because the result of Proposition 2 is not robust.

Proposition 2 may be regarded as making two separate statements:

1. Convention $U(N)$ makes each country pivotal and therefore endows individual countries with incentives to sign.

2. Because all countries have incentives to sign the Convention, the Convention enters into force. 
Suppose that the payoffs of individual countries are not exactly as specified in the model, but that each individual country may have an idiosyncratic disposition to sign the Convention. A country inclined to sign derives an excess payoff from signing that is larger than the excess benefits of procurement, minus the excess monitoring cost, minus the excess enforcement cost. A country inclined not to sign derives an excess payoff from signing that is lower than the excess benefits of procurement, minus the excess monitoring cost, minus the excess enforcement cost.

Introducing these idiosyncratic effects seems reasonable for several reasons. First, our simple model does not take into account asymmetries that may endow different countries with different incentives to sign. Second, the model does not acknowledge either the fact that the governments of some countries are involved in corrupt transaction and are therefore all but keen to witness the failure of any attempt to curb international corruption. Finally, the model also ignores the fact that governments that commit to penalizing bribery of foreign public officials may receive a benefit for a variety of reasons that range from pure altruism to gains deriving from signaling its resolve to fight corruption, and from an improved international status to more generous access to loans from the World Bank or the IMF.

When these idiosyncratic effects are recognized, Convention $U(N)$ still maximizes the incentives of individual countries to sign, but it provides no guarantee that all countries will end up signing and, therefore, that the Convention will enter into force. In other words, we are persuaded by Proposition 2's contention that making each country pivotal creates some incentives to sign. But we believe that its prediction that all countries will sign is not robust. For this reason, the rest of the paper is dedicated to an analysis of the impact of conventions on international corruption when individual countries have idiosyncratic propensities to sign a convention.

Before turning to an explicit analysis of the consequences of idiosyncratic payoff functions, we want to give a brief discussion of the extension of the result of Proposition 2 to Conventions $U(\tau), \tau=1, \ldots, N-1$. In a SPNE under Convention $U(\tau), \tau=1, \ldots, N-1$, no more than $\tau$ countries will sign the Convention. In particular, if $\tau$ is high enough in all SPNE of $\Gamma(U(\tau))$ exactly $\tau$ countries sign the Convention. This is the case because each of the $\tau$ signatory countries is pivotal to the Convention entering into force and because with a high $\tau$ a signatory country's benefits of procurement deriving from the fact that $\tau-1$ foreign countries penalize their firms operating abroad are sufficient to compensate the increase in the enforcement costs that the signatory country bears for signing the Convention. When $\tau$ is low, in all SPNE of $\Gamma(U(\tau))$ exactly $\tau-1$ countries sign the Convention. This is the case because each of the $N-\tau+1$ nonsignatory countries is pivotal to the Convention not entering into force and finds it optimal not to deviate and sign because with a low $\tau$ the benefits of procurement deriving from the fact that $\tau-1$ foreign countries penalize their firms operating abroad are not sufficient to compensate the increase in the enforcement costs that signing the Convention and causing it enter into force would entail.

The previous discussion illustrates that in a simple game such as $\Gamma(U(\tau))$ there are obvious gains in making $\tau$ as high as possible. This is the reason we chose to focus our analysis on $U(N)$. The goal of the rest of the paper is to show that the introduction of idiosyncratic components in the inclination to sign a convention leads to dramatic changes.

\section{Unilateral Conventions and Idiosyncratic Preferences}

In this section we allow the preferences of countries to differ from $\mathcal{G}_{i}(\mu, \pi, \gamma)$. Let $\sigma_{i} \in\{Y, N\}$ denote the action of signing $\left(\sigma_{i}=Y\right)$ or not $\left(\sigma_{i}=N\right)$ the Convention for country $i$ at stage 0 .

Definition 3 Let $\Gamma(\alpha, \mathcal{C})$ be the game in which Nature publicly draws $\alpha=\left(\alpha_{1}, \ldots, \alpha_{N}\right) \in \mathbb{R}^{N}$ at 
stage -1 , the governments of individual countries simultaneously decide at stage 0 whether to sign Convention $\mathcal{C}$ and then play as in $\Gamma$, with the possible restrictions that having signed Convention $C$ may entail. Preferences for firms are inherited from $\Gamma$. Governments' preferences are represented by:

$$
\widetilde{\mathcal{G}}_{i}(\sigma, \mu, \pi, \gamma)=\left\{\begin{array}{ll}
\mathcal{G}_{i}(\mu, \pi, \gamma) & \text { if } \sigma_{i}=N \\
\mathcal{G}_{i}(\mu, \pi, \gamma)+\alpha_{i} & \text { if } \sigma_{i}=Y
\end{array} .\right.
$$

Notice that, as in $\Gamma(\mathcal{C})$, in $\Gamma(\alpha, \mathcal{C})$ Convention $\mathcal{C}$ is given. This means that countries cannot propose different conventions but can only decide whether to sign Convention $\mathcal{C}$ at stage 0 of the game. In game $\Gamma(\alpha, \mathcal{C})$, the act of signing the Convention gives each individual government $i$ an additive and idiosyncratic extra utility of $\alpha_{i} \in \mathbb{R}$ that does not depend on whether other countries have signed or not the Convention and in particular on whether the Convention enters into force or not. Notice that $\alpha_{i}$ can be positive, negative, or zero. Without loss of generality we index countries so that $\alpha_{1} \geq \alpha_{2} \geq \ldots \geq \alpha_{N}$.

We now want to discuss some preliminary results that will be useful for the characterization of the SPNE of $\Gamma(\alpha, \mathcal{C})$. In particular we are interested in analyzing the impact of the decision to sign a Convention on the enforcement costs borne by a signatory country. To do this we need to analyze the changes in the continuation play and continuation utilities that may derive from an individual country's deviation from a given stage 0 action profile.

Consider a subgame starting at stage 1 after a total of $n \geq \tau$ countries have signed Convention $U(\tau)$ at stage 0 . In a SPNE of this subgame signatory countries set penalties for all their firms and nonsignatory countries set penalties only for their firms operating domestically. Consider now stage 2 and denote by $\mu^{S *}$ and $\mu^{N S *}$ the SPNE monitoring probabilities in a signatory and nonsignatory country, respectively. Similarly, let $\gamma_{-i}^{S *}$ and $\gamma_{-i}^{N S *}$ denote the SPNE probability that a firm incorporated in country $i$ is involved in a corrupt transaction in a foreign signatory or nonsignatory country, respectively.

The following Lemma characterizes the reduction in enforcement costs that a signatory country $i$ could achieve by deviating and not signing the Convention.

Lemma 3 Consider $\Gamma(\alpha, U(\tau)$ ) and an action profile at stage 0 in which $n \geq \tau$ countries (including country $i)$ sign Convention $U(\tau)$. The reduction in enforcement costs that country $i$ could achieve by deviating and not signing the Convention is

$$
D \mathcal{E C}_{i}(n)=\left[(n-1) \gamma_{-i}^{S *} \mu^{S *}+(N-n) \gamma_{-i}^{N S *} \mu^{N S *}\right] P .
$$

Proof. Immediate.

The enforcement costs deriving from signing Convention $U(\tau)$ depend on the number of signatory countries, $n$, because signing the Convention implies an enforcement cost for country $i$ that depends on the expected number of corruption cases that are uncovered. Given that this expected number is equal to the probability of corruption times the monitoring probability, it depends on the number of signatory countries, as the latter affects both probabilities of corruption and monitoring probabilities. $D \mathcal{E C}_{i}(n)$ in Lemma 3 describes the magnitude of enforcement cost savings government $i$ would attain by deviating from a profile in which it signs Convention $U(\tau)$ together with $n-1$ other countries. Notice that the enforcement cost savings depend on the number of the other countries that penalize bribing of foreign public officials. However, they depend on the specific Convention only to the extent that they are different from 0 so long as $n \geq \tau$, but are otherwise independent of $\tau$.

Consider now a profile with $n>\tau$ signatory countries. For that to be part of a SPNE of $\Gamma(\alpha, U(\tau))$ it is necessary and sufficient that neither signatory nor nonsignatory countries prefer 
to deviate. If a signatory country deviates, it loses $\alpha_{i}$ and it saves on enforcement costs, but its benefits of procurement and monitoring costs in the continuation game are unaffected. For a signatory country not to want to deviate, we therefore need, $\alpha_{i} \geq D \mathcal{E C}_{i}(n)$. If a nonsignatory country deviates, it receives $\alpha_{j}$ and it has increased enforcement costs, but its benefits of procurement and monitoring costs in the continuation game are unaffected. For a nonsignatory country not to prefer a deviation, we therefore need, $\alpha_{j}<D \mathcal{E} \mathcal{C}_{j}(n+1)$.

The previous discussion clarifies that $D \mathcal{E C}_{i}(n)$ has a prominent impact on the SPNE of $\Gamma(\alpha, U(\tau))$ and its properties. We therefore turn to its characterization. To simplify the presentation, in the following we will consider the extension of $D \mathcal{E} \mathcal{C}_{i}(n)$ to $\mathbb{R}_{+}$. The following Lemma characterizes an important property of $D \mathcal{E C}_{i}(n)$.

Lemma $4 \operatorname{DEC}_{i}(n)$ is a concave quadratic function of $n$, if $N \geq 3$

Proof. Appendix.

Lemma 4 lies at the heart of our main results and therefore deserves careful discussion. Note that Lemma 4 implies that $\operatorname{DEC}_{i}(n)$ may have an increasing portion. This means that it is possible that adding one signatory country to the Convention may imply a negative externality on the current signatory countries, in the sense that it causes enforcement costs of signatory countries to increase. This may seem surprising, because it means that the participation of an additional country in a Convention may generate a negative externality. To see why this negative externality may occur, consider the case in which there are three countries. Suppose that country 1 plans to sign Convention $U(1)$ and consider its enforcement costs when it is the only signatory and when country 2 signs as well. From Corollary 1 we know that the effect of country 2 prosecuting its firms in country 1 is beneficial to the government of country 1 .

Consider now the consequences on country 1 of country 2 prosecuting its firm active in country 3 , firm $(2,3)$. By Corollary 1 , country 3 finds it optimal to respond by augmenting the probability with which any local corrupt transaction is discovered. But the increase in the monitoring probability in country 3 has two different repercussions on the probability that firm $(1,3)$ is found to have bribed the public official of country 3. First, it creates additional deterrence. Second, it increases the probability with which a corrupt transaction is discovered. The first effect tends to decrease the probability that firm $(1,3)$ is found to have bribed the public official of country 3 , because it decreases the probability that bribing occurs. The second effect tends to increase the probability that firm $(1,3)$ is found to have bribed the public official of country 3 , because it increases the probability with which bribing is discovered if it occurs.

Given that the two effects have different signs, the net effect on the probability that firm $(1,3)$ is found to have bribed the public official of country 3 may be to decrease or increase it. Because the enforcement costs are increasing in this probability, country 1's enforcement costs may increase or decrease when country 2 signs the Convention. Note that the effect discussed above arises only if there are at least 3 countries and this is the reason why we chose to consider a case with $N$ countries rather than a simpler model with only 2 countries.

We now want to investigate when the gains from deviating and not signing a convention that derive from the savings in enforcement costs are maximal. We define

$$
\nu=\underset{n \in\{1, \ldots, N\}}{\operatorname{argmax}} D \mathcal{E C}_{i}(n) .
$$

Notice that $\nu$ is not necessarily a singleton because $D \mathcal{E C}_{i}(n)$ is a concave quadratic function in $n$ and therefore there may be two values of $n \in\{1, \ldots, N\}$ that attain the maximum. Consider now a profile in which $n$ countries sign Convention $U(1)$ at stage 0 . If a signatory country deviates from 
such a profile, its enforcement cost savings are maximal when $n \in \nu$. Given that $\nu$ characterizes the action profiles at stage 0 from which an individual deviation generates the largest enforcement cost savings, it will prove useful to discuss the incentives individual governments have to deviate from a given action profile at stage 0 .

\subsection{Equilibria with Convention U(1)}

Under Convention $U(1)$ a signatory country commits to penalizing its firms found to have bribed the public officials of all foreign countries and regardless of the number of other countries signing the Convention. Convention $U(1)$ differs from the OECD Convention but it constitutes a useful benchmark and a useful reference to discuss Conventions $U(\tau), \tau>1$, that will be analyzed in the next subsection. The next Proposition characterizes SPNE under Convention $U(1)$.

Proposition 3 Consider $\Gamma(\alpha, U(1))$.

1. A SPNE of $\Gamma(\alpha, U(1))$ always exists.

2. There may be at most one SPNE with $\min \nu$ or fewer signatory countries.

3. There may be multiple SPNE with $\min \nu+1$ or more signatory countries.

Proof. Appendix.

Proposition 3 says that in the case in which an individual country's enforcement cost savings $D \mathcal{E C}_{i}(n)$ monotonically increase with $n$ (i.e., when $\min \nu=N$ ), a unique SPNE exists. To see this suppose that two SPNE exist, the first with $N^{\prime}$ and the second with $N^{\prime \prime}>N^{\prime}$ signatory countries. Because of the symmetry of the model, in the first SPNE the $N^{\prime}$ countries with the highest $\alpha$ 's sign the Convention, and all the other countries do not. By the same argument, in the second SPNE the $N^{\prime \prime}$ countries with the highest $\alpha$ 's sign the Convention, and all the other countries do not. This means that countries $i=N^{\prime}+1, \ldots, N^{\prime \prime}$ sign the Convention in the first SPNE but not in the second. Noting that the the enforcement cost savings are larger in the second SPNE than in the first, leads to a contradiction.

When a signatory country's reduction in enforcement costs deriving from deviating and not signing, $D \mathcal{E C}_{i}(n)$, monotonically decrease with $n$ (i.e., when $\min \nu=1$ ), the previous argument cannot be applied. When $D \mathcal{E C}_{i}(n)$ monotonically decreases with $n$, instead, the fact that an additional country signs Convention $U(1)$ reduces the excess enforcement costs that any country has to bear for signing the Convention. This generates a strategic complementarity and leads to emergence of multiple SPNE.

When a signatory country's enforcement cost savings from deviating, $D \mathcal{E C}_{i}(n)$, are not monotonic in $n$ (i.e., when $1<\min \nu<N$ ), by Lemma $4, D \mathcal{E C}_{i}(n)$ is increasing for $n \leq \min \nu$ and decreasing for $n \geq \min \nu+1$. By Proposition 3, the arguments used in the previous cases can be applied separately to the increasing and the decreasing portion of $D \mathcal{E C}_{i}(n)$. This implies that there can be no more than one SPNE in the increasing portion of $D \mathcal{E C}_{i}(n)$, but there may be multiple SPNE in the decreasing portion.

The following Proposition states that SPNE with larger numbers of signatory countries Pareto dominate SPNE with a lower number of signatory countries.

Proposition 4 Suppose that $\Gamma(\alpha, U(1))$ has two $S P N E$, one with $N^{\prime}$ and one with $N^{\prime \prime}>N^{\prime}$ signatory countries. Then the SPNE with $N^{\prime \prime}$ Pareto dominates the SPNE with $N^{\prime}$ signatory countries. 
Rather than providing a formal proof of Proposition 4 in the following we provide its intuition. First, notice that all countries that do not sign in either SPNE are strictly better off in the second SPNE than in the first, because they do not bear any enforcement costs and because the benefits of procurement they enjoy are larger when a larger number of countries sign the Convention. Second, countries that sign the convention in the second equilibrium (with $N^{\prime \prime}$ signatory countries) but not in the first (with $N^{\prime}$ signatory countries), receive a higher utility in the second equilibrium than in the first. To see why this is the case, notice that if such a country were to deviate from a profile with $N^{\prime \prime}$ signatory countries, it would get higher utility than in the SPNE with $N^{\prime}$ signatory countries, because its benefits of procurement would be higher than in that case. ${ }^{12}$ Given that the utility in the SPNE has to be at least as large as the utility from any deviation, the result follows. Finally, turn to countries that sign the Convention in both SPNE. Given that additional countries with lower idiosyncratic utilities sign the Convention in the second SPNE, the enforcement costs in the second SPNE are smaller. Noticing that the benefits of procurement are higher in the equilibrium with more signatory countries concludes the argument.

\subsection{Equilibria Under the OECD Convention}

We now turn to a characterization of SPNE under Conventions $U(\tau), \tau>1$. This analysis is useful for two reasons. First, Convention $U(\tau), \tau>1$, gives a stylized description of the OECD Convention (which includes a clause requiring that a minimum number of countries, representing a minimum percentage of OECD export sign it before it enters into force) and therefore provides a framework to think about the OECD Convention's likely impact. Second, a comparison of SPNE under Convention $U(1)$ and under Conventions $U(\tau), \tau>1$, makes it possible to analyze the advantages and disadvantages of introducing a minimum threshold $\tau>1$.

Notice first that the equivalents of Propositions 3 and 4 hold for $\Gamma(\alpha, U(\tau))$. In other words $\Gamma(\alpha, U(\tau))$ always has a SPNE, it may have multiple SPNE, and in case of SPNE multiplicity, SPNE with a higher number of signatory countries Pareto dominate SPNE with a lower number of signatory countries. The proofs are straightforward extensions of the previous results and are, therefore, omitted.

We now want to make comparisons between SPNE under Conventions $U(1)$, and $U(\tau), \tau>1$. For this purpose we find it useful to define the following set of idiosyncratic utilities

$\mathcal{A}(U(\tau), n)=\left\{\alpha \in \mathbb{R}^{N}\right.$ : there exists a SPNE of $\Gamma(\alpha, U(\tau))$ with at least $n$ signatory countries $\}$.

Proposition 5 Consider $\Gamma(\alpha, U(1))$ and $\Gamma(\alpha, U(\tau))$ for $\tau>1$.

1. $\mathcal{A}(U(1), \tau) \subset \mathcal{A}(U(\tau), \tau)$ and, for $\tau<n, \mathcal{A}(U(1), n)=\mathcal{A}(U(\tau), n)$.

2. $\mathcal{A}(U(1), 1) \backslash \mathcal{A}(U(\tau), \tau) \neq \varnothing$.

Proof. Appendix.

Parts 1 and 2 of Proposition 5 reveal that introducing a threshold $\tau>1$ may have an upside and a downside, respectively.

Part 1 states first that there exist vectors of idiosyncratic utilities such that $\Gamma(\alpha, U(\tau))$ has a SPNE with at least $\tau$ signatory countries and such that $\Gamma(\alpha, U(1))$ has no such SPNE. This is true because under Convention $U(\tau)$ a signatory country's deviation from a profile with $\tau$ signatory countries leads to a reduction in the benefits of procurement, because each of the $\tau$

\footnotetext{
${ }^{12}$ This is true so long as $N^{\prime \prime}>N^{\prime}+1$, a condition that is easily shown to hold.
} 
signatory countries is pivotal to the Convention entering into force. Given that this loss does not occur under Convention $U(1)$, the incentives to deviate under Convention $U(\tau)$ are fewer than under Convention $U(1)$ and the result follows. ${ }^{13}$

Part 1 also states that the set of idiosyncratic utilities such that there exists a SPNE with at least $n$ signatory countries is the same under Convention $U(1)$ as under Convention $U(\tau)$, if the threshold is strictly lower than $n$. This means that all SPNE with $n$ signatory countries under Convention $U(1)$ are also SPNE when a threshold $\tau<n$ is introduced. In other words, the introduction of a threshold $\tau<n$ does not make a SPNE with $n$ signatory countries more likely in the sense that the sets of idiosyncratic utilities which guarantee that such a SPNE exists under the two Conventions are identical.

Summarizing, part 1 says that the introduction of a threshold $\tau$ is beneficial to support a SPNE with exactly $\tau$ signatory countries, but is otherwise useless.

Part 2 states that there are $\alpha$ 's that are such that a SPNE with a positive number of signatory countries exists under $U(1)$ and also such that under $U(\tau)$ there is no SPNE in which the Convention enters into force. This means that there are values of $\alpha$ for which the introduction of a minimum threshold leads from a convention entering into force with a possibly limited but positive number of signatory countries to a convention that does not enter into force. Notice also that the same result can be shown to apply to the comparison of SPNE under two different thresholds, $\tau^{\prime}$ and $\tau^{\prime \prime}$, with $1 \leq \tau^{\prime}<\tau^{\prime \prime} \leq N$. In other words, increasing the threshold is always risky in that it may lead to the convention not entering into force.

Our interpretation of Proposition 5 is that introducing a minimum threshold that has to be met before a Convention enters into force is a sensible requirement that may turn out to be harmful when it is set in ignorance of possible idiosyncratic components of individual countries' inclinations to sign a convention against bribery in international business transactions. In particular, a threshold is useful when it makes every signatory country pivotal. But setting an ambitiously high threshold may lead to a situation in which there is no SPNE in which the Convention enters into force.

\section{An Alternative Convention: The Impact of Reciprocity}

Convention $R$ proposes an alternative institutional design to combat corruption in international business transactions.

Definition 4 Convention $R$ : If a country signs the Convention, the country commits to impose the same penalty on all domestically incorporated firms found to have bribed public officials of all other signatory countries.

Compared to the unilateral conventions analyzed in the previous section, Convention $R$ makes use of the possibility of excluding countries from the beneficial effects of the international fight against bribing of foreign public officials, unless they actively contribute to this fight. Under Convention $U(\tau)$, if country $i$ decides not to sign, it loses idiosyncratic utility $\alpha_{i}$ and it saves on enforcement costs. When $n=\tau$, moreover, a deviation also leads to the loss deriving from the reduction in the benefits of procurement. Under Convention $R$, if country $i$ decides not to sign, there are two important novel effects. First, if country $i$ does not sign Convention $R$, it saves on enforcement costs, but the savings are smaller than under Convention $U(\tau)$, in the

\footnotetext{
${ }^{13}$ Notice that part 1 also claims that if $\alpha \in \mathcal{A}(U(1), \tau)$ then $\alpha \in \mathcal{A}(U(\tau), \tau)$. This result is also an immediate consequence of the fact that the incentive to deviate from a profile with $\tau$ signatory countries are larger under $U(1)$ than under $U(\tau)$.
} 
event in which not all foreign countries sign the Convention. This derives from the fact that Convention $R$ requires penalizing bribing of public officials of signatory countries only. Given that this leads to lower enforcement costs, the savings deriving from not signing are smaller. Second, if country $i$ decides not to sign Convention $R$, it loses the beneficial effects deriving from signatory countries' commitment to penalize their own firms operating in country $i$, because this penalization is conditional on country $i$ also signing the Convention. As was stated in Corollary 1 the utility of the government of country $i$ is increasing in the sum of penalties imposed by foreign countries on their firms operating in country $i, \partial \mathcal{G}_{i} / \partial \pi_{F i}>0$.

The previous discussion clarifies that Convention $R$ provides the governments of individual countries additional incentives to sign when they believe that not all countries are likely to sign. This is because Convention $R$ creates a direct beneficial effect of signing and it reduces the cost savings from not signing when less than full participation is expected, i.e., in the cases in which signing the Convention is likely to generate high costs and reduced benefits.

In the following we analyze the consequences on governments' behavior of the incentives created by Convention $R$. We start by studying SPNE in $\Gamma(0, R)$, the game in which individual governments simultaneously decide whether to sign Convention $R$ at stage 0 and in which their idiosyncratic utilities they receive from signing the agreement are identically zero, $\alpha=0$.

Proposition 6 In $\Gamma(0, R)$ there is a unique SPNE in which all $N$ countries sign Convention $R$ at stage 0 .

The proof of Proposition 6 follows along the same lines as the proof of Proposition 2 and is therefore omitted.

Before turning to the analysis of Convention $R$ when individual countries have idiosyncratic utilities, it is useful to discuss Proposition 6 and in particular to compare it to Proposition 2. Proposition 6 states that $\Gamma(0, R)$ has a unique SPNE in which all countries sign Convention $R$. In a similar way, Proposition 2 established that $\Gamma(0, U(N))$ has a unique SPNE in which all countries sign Convention $U(N)$. This implies that the equilibrium payoffs under the two Conventions are identical. But we want to highlight that there is a sense in which the results of the two Propositions may be regarded as different and, in particular, that the disposition of countries to participate in the fight against international corruption is more robust under Convention $R$ than under Convention $U(N)$.

Notice that in both cases cooperation is achieved by making sure that each country $i$ receives the benefit deriving from the fact that the other countries will prosecute their firms found to have bribed the public official of country $i$ only if country $i$ itself signs the Convention. Under Convention $U(N)$ this is achieved by making each country pivotal to the Convention entering into force. Under Convention $R$ this is achieved by conditioning a country's benefits to its participation in the Convention. Notice, however, that under Convention $U(N)$ if, for some reason, it is believed that at least one country will not sign the Convention, then all countries are indifferent between signing or not. Under Convention $R$ the situation is radically different, because, so long as a country believes that at least one other country signs the Convention, it finds it strictly profitable to sign the Convention as well.

We now turn to a characterization of SPNE under Convention $R$ when individual countries have idiosyncratic components in their payoff functions. Notice first that the results of Propositions 3 and 4 extend to $\Gamma(\alpha, R)$. In other words, $\Gamma(\alpha, R)$ always has a SPNE, it may have multiple SPNE, and in case of SPNE multiplicity, SPNE with a higher number of signatory countries Pareto dominate SPNE with a lower number of signatory countries. The proofs are straightforward extensions of Propositions 3 and 4 and are, therefore, omitted. 
To make comparisons between SPNE under Conventions $U(\tau)$ and $R$ we define the following set:

$$
\mathcal{A}(R, n)=\left\{\alpha \in \mathbb{R}^{N}: \text { there exists a SPNE of } \Gamma(\alpha, R) \text { with at least } n \text { signatory countries }\right\} .
$$

Proposition 7 Consider $\Gamma(\alpha, U(\tau))$ and $\Gamma(\alpha, R)$.

1. $\mathcal{A}(U(\tau), n) \subset \mathcal{A}(R, n)$ for $\tau \leq n$ and $\tau<N$.

2. $\mathcal{A}(U(N), N)=\mathcal{A}(R, N)$

Proof. Appendix.

Part 1 of Proposition 7 states that there exist vectors of idiosyncratic utilities such that $\Gamma(\alpha, R)$ has a SPNE with at least $\tau<N$ signatory countries and such that $\Gamma(\alpha, U(\tau))$ has no such SPNE, while the reverse is impossible. To see why this is true, consider the case in which $\Gamma(\alpha, U(\tau))$ admits a SPNE with exactly $\tau$ signatory countries. ${ }^{14}$ When a signatory country deviates from such a profile it loses its idiosyncratic payoff $\alpha_{i}$, it saves on the enforcement costs, but it will also cause the Convention not entering into force and will therefore bear an additional loss deriving from the reduction in the benefits of procurement. Consider the same profile under Convention $R$ and consider a deviation of a signatory country. The deviator loses its idiosyncratic payoff $\alpha_{i}$, it saves on the enforcement costs and it also bears the loss deriving from the reduction in the benefits of procurement. The first and the third element are identical under Convention $U(\tau)$ as under Convention $R$. But the enforcement cost savings are smaller when deviating under Convention $R$, because Convention $R$ only requires prosecuting the firms bribing the public officials of the other signatory countries, which, in the case contemplated in Part 1, are less than the total number of countries, $N$. This means that the incentives to deviate from a profile with $\tau<N$ signatory countries are fewer under Convention $R$ than under Convention $U(\tau)$, and the result follows. ${ }^{15}$

Part 2 states that set of idiosyncratic utilities such that there exists a SPNE with $N$ signatory countries is the same under Convention $U(N)$ as under Convention $R$. The reason for this is that with $\tau=N$, the reduction of the benefits of procurement to a country that deviates from a profile in which $N$ countries sign the convention is the same under $U(\tau)$ or under $R$. Notice that from Proposition 2, $0 \in \mathcal{A}(U(N), N)$ and from Proposition 6, $0 \in \mathcal{A}(R, N)$. Part 2 generalizes this result by showing that the set of idiosyncratic utilities that lead to a SPNE with $N$ signatory countries are the same under $U(N)$ and $R$.

Our interpretation of the previous results is that there are two reasons why Convention $R$ may be preferred to Convention $U(\tau)$. The first is clarified by part 1 of Proposition 7 that suggests that a reciprocal convention is more likely to bring countries together in the fight against international corruption than a unilateral convention, because SPNE with any given number of signatory countries arise with a larger set of parameter constellations in the former than in the latter case. To see the second reason, notice that part 2 of Proposition 7 does not say that if $\tau$ is set high enough a unilateral Convention leads to the same result as a reciprocal convention. The reason is that part 2 of Proposition 7 does not say that when $\alpha \notin \mathcal{A}(U(N), N)=\mathcal{A}(R, N)$ the set of SPNE under $U(N)$ or under $R$ are the same. In fact, under $U(N)$ the Convention will

\footnotetext{
${ }^{14}$ The analysis of the case in which a SPNE exists with strictly more than $\tau$ signatory countries proceeds along very similar lines and is therefore not discussed in the text.

${ }^{15}$ Notice that Part 1 also claims that if $\alpha \in \mathcal{A}(U(\tau), \tau)$, then $\alpha \in \mathcal{A}(R, \tau)$. This result is also a consequence of the fact that the incentive to deviate from a profile with $\tau$ signatory countries are larger under $U(\tau)$ than under $R$. Notice also, that the arguments above do not rule out that for a given $\alpha$, Convention $R$ provides enough incentives for additional countries to sign, and therefore that a SPNE with strictly more than $\tau$ signatory countries exists.
} 
not enter into force in any SPNE, but it is possible that a SPNE in which a positive number of countries signing Convention $R$ exists.

In other words, our discussion above clarifies that there are reasons to believe that a unilateral convention is risky because it may lead to no results in the fight against international corruption, especially when the convention sets ambitious goals through a high threshold. By contrast, a reciprocal convention creates more incentives to participate in the fight against international corruption and at the same time allows individual countries to gauge their ambitions through their equilibrium play.

\section{Discussion}

This paper proposes a simple theoretical framework to study the enforcement of penalties for bribing foreign public officials. The participation of foreign firms is commonly believed to promote competition and efficiency, but corruption in international business transactions is facilitated by the fact that it is often very difficult or very costly to enforce penalties on foreign firms and nationals. We analyze the ways in which international conventions may help resolve this problem by requiring signatory countries to penalize their firms that are found to have bribed foreign public officials.

We first study the incentives to sign international conventions styled along the lines of the OECD's "Convention on Combating Bribery of Foreign Public Officials in International Business Transactions." In this type of convention a signatory country commits to unilaterally penalize its firms that are found to have bribed public officials of any foreign countries, regardless of whether these countries reciprocate or not. We find that this type of convention may succeed in fostering some degree of international cooperation in fighting corruption, but that it may lead to no advances when it sets goals which are too ambitious.

We then analyze a different type of convention that includes a reciprocity clause which specifies that a signatory country commits to penalizing its firms that are found to have bribed public officials of foreign signatory countries, i.e., only of reciprocating countries. We show that this has two important effects. First, it reduces the enforcement costs deriving from signing the convention when not all countries sign the convention. Second, it implies a loss for a country that decides not to sign, because the advantages deriving from the fact that the foreign firms operating in the country are subject to corruption penalties accrue only if the country signs the convention. We show that the ultimate consequences of these effects are that a convention with a reciprocity provision is more conducive to international cooperation and may therefore lead to substantial gains in terms of reducing corruption in international business transactions.

For ease of exposition our results are derived for the case in which the probability of a firm succeeding in bribing a public official depends on the bribe it bids, but is independent of the bribes bid by its competitors. Our results do not depend on this assumption, but can be obtained for a more general model in which the probability of any one firm succeeding in bribing the public official depends negatively on the bribes bid by its competitors.

Our analysis is an initial step towards the understanding of international conventions to combat corruption and it therefore relies on a simple model. We believe that future research may lead to advances in two different directions.

First, our model is silent about various additional effects of different types of conventions. Because of its reduced risk, for instance, signing Convention $R$ is likely to be perceived as a politically compelling option. By this, we mean that a government not willing to confront corruption may find it easy to argue that a unilateral convention is likely to generate high costs and very 
limited benefits, but that this argument is much less persuasive when waged against a reciprocal convention. Because compliance with a reciprocal convention entitles a country to enjoy its benefits, a reciprocal convention, moreover, is also more likely to be accompanied by an effective surveillance system. For the same reason, however, it should not come as a surprise if an inspector from a given country had perverse motives in defending that another country is not complying with the convention.

Second, our model has made two important assumptions. The first is to deal with a symmetric environment in which, other things being equal, firms from any country have the same probability of selling in any other country. This ignores the fact that the patterns of international trade also establish a pattern of corruption trade and leads to a symmetric convention in which all countries play the same role. A more realistic model would recognize asymmetries and is likely to prescribe different behaviors on the part of corruption importers and exporters. ${ }^{16}$ The second is that we have dealt with a complete information environment in which all countries know their payoff functions and in particular their idiosyncratic inclinations to sign conventions. A more realistic environment would allow for incomplete information and for the possibility that countries' inclinations to combat corruption are correlated.

Future research dealing with some of the issues mentioned above is likely to generate substantial progress in our understanding of policies designed to curb corruption in international business transactions.

\footnotetext{
${ }^{16}$ On this issue see Davis (2002) which analyzes the incentives to join an anti-bribery convention of payor countries (countries where bribing companies are incorporated) and payee countries (countries where bribed public officials reside).
} 


\section{A Appendix}

\section{A.1 Proof of Lemma 1}

Firm $(i, j)$ 's maximization problem is

$$
\max _{\beta_{i j}} \gamma_{i j}\left[(\bar{K}-\underline{K})-\beta_{i j}-\mu_{j} \pi_{i j}\right]=\frac{\beta_{i j}}{B}\left[(\bar{K}-\underline{K})-\beta_{i j}-\mu_{j} \pi_{i j}\right] .
$$

The first order condition is

$$
\frac{1}{B}\left[(\bar{K}-\underline{K})-2 \beta_{i j}-\mu_{j} \pi_{i j}\right]=0 .
$$

Given that the second order condition is satisfied (because $-2 / B<0$ ), the Lemma follows.

\section{A.2 Proof of Lemma 2}

From Lemma 1, the probability of corruption in country $i$ is

$$
\gamma_{i}=\frac{1}{2 B}\left[N(\bar{K}-\underline{K})-\mu_{i} \sum_{j=1}^{N} \pi_{j i}\right]
$$

Given this, the problem for the government of country $i$ in stage 2 is

$$
\max _{\mu_{i}}\left(1-\gamma_{i}\right)(\bar{V}-\bar{K})+\gamma_{i}(\underline{V}-\bar{K})-\frac{M}{2} \mu_{i}^{2}-\sum_{j=1}^{N} \gamma_{i j} \mu_{j} \frac{\pi_{i j}}{\pi} P .
$$

From (7) and (8) this problem is equivalent to

$$
\max _{\mu_{i}} \frac{1}{2 B} \mu_{i}\left(\sum_{j=1}^{N} \pi_{j i}(\bar{V}-\underline{V})-\frac{\pi_{i i}}{\bar{\pi}} P(\bar{K}-\underline{K})\right)+\frac{1}{2 B}\left(\frac{\pi_{i i}}{\bar{\pi}} P \pi_{i i}-M B\right) \mu_{i}^{2} .
$$

The first order condition for an interior solution is

$$
\frac{1}{2 B}\left(\sum_{j=1}^{N} \pi_{j i}(\bar{V}-\underline{V})-\frac{\pi_{i i}}{\bar{\pi}} P(\bar{K}-\underline{K})\right)+\frac{1}{B}\left(\frac{\pi_{i i}}{\bar{\pi}} P \pi_{i i}-M B\right) \mu_{i}=0
$$

Assuming that the second order condition is satisfied,

$$
\frac{\pi_{i i}}{\bar{\pi}} P \pi_{i i}-M B<0,
$$

we obtain

$$
\mu_{i}=\frac{(\bar{V}-\underline{V}) \sum_{j=1}^{N} \pi_{j i}-\frac{\pi_{i i}}{\bar{\pi}} P(\bar{K}-\underline{K})}{2\left(M B-\frac{\pi_{i i}}{\bar{\pi}} P \pi_{i i}\right)} .
$$

Notice that if $\sum_{j=1}^{N} \pi_{j i} \geq \bar{\pi}$, (5) implies that $\mu_{i}>0$. 


\section{A.3 Proof of Proposition 1}

Recall that by Lemma $2, \sum_{j=1}^{N} \pi_{j i} \geq \bar{\pi}$ for $j=1, \ldots, N$ implies that $\mu_{j}>0, j=1, \ldots, N$. Simple inspection of the objective function of the government of country $i=1, \ldots, N$, implies that in a SPNE

$$
\pi_{i j}=0
$$

for $i=1, \ldots, N$ and $j \neq i$. We now want to show that (5) is sufficient to guarantee that in a SPNE

$$
\pi_{i i}=\bar{\pi}
$$

for $i=1, \ldots, N$. To see this, consider $\pi^{\prime \prime}$ and $\pi^{\prime}$ that differ only in that

$$
\begin{aligned}
& \pi_{i i}^{\prime}=0 \\
& \pi_{i i}^{\prime \prime}=\bar{\pi}
\end{aligned}
$$

We now compare government $i$ 's utility from setting $\pi_{i i}=\bar{\pi}$ or $\pi_{i i}=0$ for an arbitrary value of $\mu_{i}$ and for $\gamma_{i}$ and $\gamma_{i j}$ given by (8) and (9)

$$
\begin{aligned}
\mathcal{G}_{i}\left(\mu, \pi^{\prime \prime}, \gamma\right)-\mathcal{G}_{i}\left(\mu, \pi^{\prime}, \gamma\right) & =\frac{(\bar{V}-\underline{V})}{2 B} \mu_{i} \bar{\pi}-\frac{1}{2 B} \mu_{i}\left[(\bar{K}-\underline{K})-\mu_{i} \bar{\pi}\right] P \\
& >\frac{\mu_{i}^{2} \bar{\pi} P}{2 B}>0
\end{aligned}
$$

with the first inequality following from (5). Notice that the previous inequality implies that

$$
\max _{\mu_{i} \in[0,1]} \mathcal{G}_{i}\left(\mu, \pi^{\prime \prime}, \gamma\right)-\max _{\mu_{i \in[0,1]}} \mathcal{G}_{i}\left(\mu, \pi^{\prime}, \gamma\right)>0
$$

if

$$
\underset{\mu_{i} \in[0,1]}{\operatorname{argmax}} \mathcal{G}_{i}\left(\mu, \pi^{\prime \prime}, \gamma\right)>0,
$$

a condition which is satisfied by Lemma 2. This in turn means that under (5) in a SPNE of $\Gamma$, the government of each country $i$ will penalize the domestic firm that operates in the country. Summarizing, we get

$$
\pi_{i j}^{*}=\left\{\begin{array}{ll}
\bar{\pi} & \text { if } j=i \\
0 & \text { if } j \neq i
\end{array} .\right.
$$

The rest of the results stated in Proposition 1 follow by straightforward substitutions.

\section{A.4 Proof of Corollary 1}

Differentiating (10) with respect to $\pi_{F i}$ we obtain

$$
\frac{\partial \mu_{i}}{\partial \pi_{F i}}=\frac{(\bar{V}-\underline{V})}{2\left(M B-\frac{\pi_{i i}}{\pi} P \pi_{i i}\right)}>0,
$$

with the inequality following from that fact that the second order condition for the government's problem ensures that the denominator is positive.

Rewrite corruption in country $i$ as

$$
\gamma_{i}=\frac{1}{2 B}\left[N(\bar{K}-\underline{K}) \pi_{F i}-\mu_{i}\left(\bar{\pi}+\pi_{F i}\right)\right]
$$


Differentiating with respect to $\pi_{F i}$ we obtain

$$
\frac{\partial \gamma_{i}}{\partial \pi_{F i}}=-\frac{\partial \mu_{i}}{\partial \pi_{F i}}\left(\bar{\pi}+\pi_{F i}\right)-\mu_{i}<0
$$

Consider now government $i$ 's best response to a given $\pi_{i F}$. To show that $\partial \mathcal{G}_{i} / \partial \pi_{i F}>0$, it is sufficient to observe that when $\pi_{i F}$ is increased, government $i$ 's utility is higher even if its play is unchanged.

\section{A.5 Proof of Proposition 2}

Since we assume that whenever indifferent between signing or not, a country signs the Convention, it is immediate to recognize that there is a unique SPNE with either $N-1$ or $N$ countries signing the agreement. In the following we show that the unique SPNE is for all countries to sign the agreement.

Consider an arbitrary government $i$ and assume that all the other $N-1$ countries sign the Convention. We want to show that government $i$ 's best response is to sign the Convention.

The utility of the government of country $i$, if it signs the Convention is

$$
\mathcal{G}_{i}^{S}=X+(\bar{V}-\bar{K}) N \mu_{i}-\frac{M}{2} \mu_{i}^{2}-\sum_{j=1}^{N} \gamma_{i j} \mu_{j} P
$$

where

$$
X=(\bar{V}-\bar{K})+\frac{N(\bar{V}-\underline{V})(\bar{K}-\underline{K})}{2 B} .
$$

The utility of the government of country $i$, when it does not sign the Convention is

$$
\begin{aligned}
\mathcal{G}_{i}^{N S} & =X+(\bar{V}-\bar{K}) \mu_{i}-\frac{M}{2} \mu_{i}^{2}-\gamma_{i i} \mu_{i} P \\
& =X+(\bar{V}-\bar{K}) \mu_{i}-\frac{M}{2} \mu_{i}^{2}-\frac{P}{2 B}\left[(\bar{K}-\underline{K})-\mu_{i} \bar{\pi}\right] \mu_{i}
\end{aligned}
$$

We want to show that $\mathcal{G}_{i}^{S}>\mathcal{G}_{i}^{N S}$.

Let $\mu^{S *}$ denote the SPNE monitoring probability in a signatory country in a subgame starting after $N$ countries sign the Convention. Let $\mu^{N S *}$ denote the SPNE monitoring probability in a nonsignatory country in a subgame starting after $N-1$ countries sign the Convention. We then have

$$
\begin{aligned}
\mathcal{G}_{i}^{S} & =X+(\bar{V}-\bar{K}) N \mu^{S *}-\frac{M}{2}\left(\mu^{S *}\right)^{2}-N \frac{P}{2 B}\left[(\bar{K}-\underline{K})-\mu^{S *} \bar{\pi}\right] \mu^{S *} \\
& =X+N\left[(\bar{V}-\bar{K}) \mu^{S *}-\frac{M}{2 N}\left(\mu^{S *}\right)^{2}-\frac{P}{2 B}\left[(\bar{K}-K)-\mu^{S *} \bar{\pi}\right] \mu^{S *}\right] \\
& \geq X+N\left[(\bar{V}-\bar{K}) \mu^{N S *}-\frac{M}{2 N}\left(\mu^{N S *}\right)^{2}-\frac{P}{2 B}\left[(\bar{K}-\underline{K})-\mu^{N S *} \bar{\pi}\right] \mu^{N S *}\right] \\
& >X+N\left[(\bar{V}-\bar{K}) \mu^{N S *}-\frac{M}{2}\left(\mu^{N S *}\right)^{2}-\frac{P}{2 B}\left[(\bar{K}-\underline{K})-\mu^{N S *} \bar{\pi}\right] \mu^{N S *}\right] \\
& >X+(\bar{V}-\bar{K}) \mu^{N S *}-\frac{M}{2}\left(\mu^{N S *}\right)^{2}-\frac{P}{2 B}\left[(\bar{K}-\underline{K})-\mu^{N S *} \bar{\pi}\right] \mu^{N S *}=\mathcal{G}_{i}^{N S}
\end{aligned}
$$

with the first inequality following from the fact that $\mu^{S *}$ is the optimal monitoring probability for a signatory country and the last inequality deriving from the fact that $\mu^{N S *}>0$ implies

$$
(\bar{V}-\bar{K}) \mu^{N S *}-\frac{M}{2}\left(\mu^{N S *}\right)^{2}-\frac{P}{2 B}\left((\bar{K}-\underline{K})-\mu^{N S *} \bar{\pi}\right) \mu^{N S *}>0 .
$$




\section{A.6 Proof of Lemma 4}

Recall from Lemma 3

$$
D \mathcal{E C}_{i}(n)=\left[(n-1) \gamma_{-i}^{S *} \mu^{S *}+(N-n) \gamma_{-i}^{N S *} \mu^{N S *}\right] P .
$$

where

$$
\begin{aligned}
\gamma_{-i}^{S *} & =\frac{1}{2 B}\left[(\bar{K}-\underline{K})-\mu^{S *} \bar{\pi}\right] \\
\gamma_{-i}^{N S *} & =\frac{1}{2 B}\left[(\bar{K}-\underline{K})-\mu^{N S *} \bar{\pi}\right] \\
\mu^{S *} & =\frac{(n-1)(\bar{V}-\underline{V}) \bar{\pi}-(\bar{K}-\underline{K}) P}{2(B M-\bar{\pi} P)} \\
\mu^{N S *} & =\frac{n(\bar{V}-\underline{V}) \bar{\pi}-(\bar{K}-\underline{K}) P}{2(B M-\bar{\pi} P)} .
\end{aligned}
$$

Letting

$$
\begin{aligned}
F & =\frac{(\bar{K}-\underline{K})}{2 B} \\
G & =\frac{(\bar{V}-\underline{V}) \bar{\pi}}{2(B M-\bar{\pi} P)} \\
H & =\frac{(\bar{K}-\underline{K}) P}{2(B M-\bar{\pi} P)}
\end{aligned}
$$

we obtain

$$
\begin{aligned}
D \mathcal{E C}_{i}(n)= & {\left[(n-1)\left(F-\mu^{S *} \frac{\bar{\pi}}{2 B}\right) \mu^{S *}+(N-n)\left(F-\left(\mu^{S *}+G\right) \frac{\bar{\pi}}{2 B}\right)\left(\mu^{S *}+G\right)\right] P } \\
= & {\left[(N-1)\left(F-\mu^{S *} \frac{\bar{\pi}}{2 B}\right) \mu^{S *}+(N-n)\left(G\left(F-\left(\mu^{S *}+G\right) \frac{\bar{\pi}}{2 B}\right)-G \mu^{S *} \frac{\bar{\pi}}{2 B}\right)\right] P } \\
= & {\left[(N-1)\left(F-(G(n-1)-H) \frac{\bar{\pi}}{2 B}\right)(G(n-1)-H)\right.} \\
& \left.+(N-n)\left(G\left(F-(G n-H) \frac{\bar{\pi}}{2 B}\right)-G(G(n-1)-H) \frac{\bar{\pi}}{2 B}\right)\right] P .
\end{aligned}
$$

Letting

$$
\begin{aligned}
Q_{0} & =-(N-1)(G+H)\left(F+(G+H) \frac{\bar{\pi}}{2 B}\right)+N G F+2 N G H \frac{\bar{\pi}}{2 B}+N G^{2} \frac{\bar{\pi}}{2 B} \\
Q_{1} & =-(N-1)\left(F+2(G+H) \frac{\bar{\pi}}{2 B}\right) G-2 N G^{2} \frac{\bar{\pi}}{2 B}-G F-2 G H \frac{\bar{\pi}}{2 B}-G^{2} \frac{\bar{\pi}}{2 B} \\
Q_{2} & =-(N-1) G^{2} \frac{\bar{\pi}}{2 B}+2 G^{2} \frac{\bar{\pi}}{2 B}=(3-N) G^{2} \frac{\bar{\pi}}{2 B}
\end{aligned}
$$

we get

$$
D_{\mathcal{E}} \mathcal{C}_{i}(n)=\left(Q_{0}+Q_{1} n+Q_{2} n^{2}\right) P
$$

Note that if $N \geq 3, Q_{2} \leq 0$ and $D \mathcal{E C}_{i}(n)$ is concave in $n$. 


\section{A.7 Proof of Proposition 3}

Consider $\Gamma(\alpha, U(1))$. Recall that we assume that $\alpha_{1} \geq \ldots \geq \alpha_{N}$ and that whenever indifferent between signing or not, a country signs the Convention. Given this a profile in which $N^{\prime}$ countries the Convention may be part of a SPNE if and only if

$$
\begin{aligned}
\alpha_{N^{\prime}} & \geq \operatorname{DE\mathcal {C}}_{i}\left(N^{\prime}\right) \\
\alpha_{N^{\prime}+1} & <\operatorname{DEC}_{i}\left(N^{\prime}+1\right)
\end{aligned}
$$

We first want to establish the existence of SPNE. If $\alpha_{1}<D \mathcal{E C}_{1}(1)$, there exists a SPNE in which no country signs the convention. When $\alpha_{1} \geq D \mathcal{G}_{1}(1)$, there are two cases:

1. There exists a country $j$ such that

$$
\begin{aligned}
\alpha_{i} & \geq \operatorname{DEC}_{i}(j-1) \text { for all } i<j \\
\alpha_{j} & <\operatorname{DEC}_{j}(j) .
\end{aligned}
$$

In this case there exists a SPNE in which only countries $i=1, \ldots, j-1$ sign the convention

2. There exists no country $j$ such that $\alpha_{j}<D \mathcal{E C}_{j}(j)$. In this case $\alpha_{N} \geq D \mathcal{E C}_{N}(N)$ and there exists a SPNE in which all countries sign the convention.

We now want to show that $\Gamma(\alpha, U(1))$ admits at most one $\mathrm{SPNE}$ with $\min \nu$ or fewer signatory countries, but multiple SPNE with $\min \nu+1$ or more signatory countries. By definition of $\nu$, $D \mathcal{E C}_{i}(n)$ is increasing for all $n \leq \min \nu$ and decreasing for all $n \geq \min \nu+1$.

Consider first $n \leq \min \nu$ and assume that there is a SPNE in which $N^{\prime} \leq \min \nu$ countries sign the Convention. This implies that

$$
\begin{aligned}
\alpha_{N^{\prime}} & \geq \operatorname{DEC}_{N^{\prime}}\left(N^{\prime}\right) \\
\alpha_{N^{\prime}+1} & <D \mathcal{E C}_{N^{\prime}+1}\left(N^{\prime}+1\right) .
\end{aligned}
$$

But then it is impossible to have another SPNE with $N^{\prime \prime} \in\left\{N^{\prime}+1, \ldots, \min \nu\right\}$ signatory countries because

$$
\alpha_{N^{\prime \prime}} \geq D \mathcal{E C}_{N^{\prime \prime}}\left(N^{\prime \prime}\right)
$$

cannot be satisfied for $N^{\prime \prime} \in\left\{N^{\prime}+1, \ldots, \min \nu\right\}$, given that

$$
\alpha_{N^{\prime}+1} \geq \alpha_{N^{\prime \prime}}
$$

and

$$
\operatorname{DEC}_{i}\left(N^{\prime \prime}\right)>\operatorname{DEC}_{N^{\prime}}\left(N^{\prime}\right)
$$

$N^{\prime \prime} \in\left\{N^{\prime}+1, \ldots, \min \nu\right\}$.

Consider now $n \geq \min \nu+1$. Assume that there is a SPNE in which only $N^{\prime} \geq \min \nu+1$ countries sign the Convention. This implies that

$$
\begin{aligned}
\alpha_{N^{\prime}} & \geq D \mathcal{E C}_{N^{\prime}}\left(N^{\prime}\right) \\
\alpha_{N^{\prime}+1} & <D \mathcal{E C}_{N^{\prime}+1}\left(N^{\prime}+1\right) .
\end{aligned}
$$


Given that $D \mathcal{E C}_{i}(n)$ is decreasing for $n \geq \min \nu+1$ there exists an $\alpha \in \mathbb{R}^{N}$ such that

$$
\begin{aligned}
\alpha_{N^{\prime}+k} & \geq D \mathcal{E C}_{N^{\prime}+k}\left(N^{\prime}+k\right) \\
\alpha_{N^{\prime}+k+1} & <D \mathcal{E C}_{N^{\prime}+k+1}\left(N^{\prime}+k+1\right)
\end{aligned}
$$

for $k \geq 2$. This means that there exists an $\alpha \in \mathbb{R}^{N}$ such that $\Gamma(\alpha, U(1))$ has two SPNE, with $N^{\prime} \geq \min \nu+1$ and $N^{\prime \prime}=N^{\prime}+k>\min \nu+1$ signatory countries, respectively. Notice that the condition $k \geq 2$ is necessary, because for $k=1$, (14) would contradict (13).

\section{A.8 Proof of Proposition 5}

Part 1: Consider a SPNE with $n>\tau$ signatory countries. Given that deviation payoffs for both signatory and nonsignatory countries are identical under $U(1)$ and under $U(\tau)$, we get $\mathcal{A}(U(1), n)=\mathcal{A}(U(\tau), n)$.

Consider now an $\alpha$ such that a SPNE with $\tau$ signatory countries under $U(1)$ exists. This implies that the deviation payoffs for all signatory countries are nonpositive. For signatory countries, $i=1, \ldots, \tau$ we therefore have

$$
\operatorname{DEC}_{i}(\tau)-\alpha_{i} \leq 0
$$

Recalling that we assume that, if indifferent a country signs the Convention, for nonsignatory countries $i=\tau+1, \ldots, N$ we have

$$
\alpha_{i}-D \mathcal{E C}_{i}(\tau+1)<0
$$

Notice that under $U(\tau)$ the only difference that arises is that a deviation for a signatory country also brings about a reduction in the benefits of procurement. This implies that (16) is a sufficient condition for the deviation payoffs to signatory countries to be negative under $U(\tau)$ and therefore that $\alpha \in \mathcal{A}(U(1), \tau)$ implies that $\alpha \in \mathcal{A}(U(\tau), \tau)$

We now want to show that there exists $\alpha$ 's that belong to $\mathcal{A}(U(\tau), \tau)$ but not to $\mathcal{A}(U(1), \tau)$. Let $\alpha^{*} \in \mathbb{R}^{N}$ be such that country $\tau$ is exactly indifferent between deviating or not from a profile in which $\tau$ countries sign Convention $U(1)$

$$
\alpha_{\tau}^{*}-D \mathcal{E C}_{i}(\tau)=0
$$

and such that the rest of the signatory countries strictly prefer to sign and nonsignatory countries prefer not to sign. Consider now $\alpha^{* *} \in \mathbb{R}^{N}$ such that

$$
\begin{aligned}
& \alpha_{i}^{* *}=\alpha_{i}^{*}-\varepsilon \text { for } i=1, \ldots, \tau \\
& \alpha_{i}^{* *}=\alpha_{i}^{*}-\delta \text { for } i=\tau+1, \ldots, N .
\end{aligned}
$$

Consider $\delta>0$ such that for all $\varepsilon \in(0, \delta), \alpha^{* *} \notin \mathcal{A}(U(1), \tau)$. Given that a signatory country's deviation under $U(\tau)$ also leads to a reduction in the benefits of procurement, a signatory country's deviation payoff is lower and this implies that there exist $\varepsilon \in(0, \delta)$ such that $\alpha^{* *} \in \mathcal{A}(U(\tau), \tau)$.

Part 2: Consider an $\alpha$ such that $\alpha_{\tau-1}$ is sufficiently large and $\alpha_{\tau}$ is sufficiently small. Then, $\alpha \in \mathcal{A}(U(1), 1)$ but $\alpha \notin \mathcal{A}(U(\tau), \tau)$, for all $\tau>1 .{ }^{17}$

\footnotetext{
${ }^{17}$ In fact notice that $\alpha \in \mathcal{A}(U(\tau-1), \tau-1)$ but $\alpha \notin \mathcal{A}(U(\tau), \tau)$.
} 


\section{A.9 Proof of Proposition 7}

Part 1: Consider a profile with $\tau$ signatory countries and suppose it may be part of a SPNE of $U(\tau)$. This implies that for every signatory country $i=1, \ldots, \tau, D \mathcal{E C}_{i}(\tau)-\alpha_{i}$ has to be at least as large as the reduction of the benefits of procurement which takes place because a country's unilateral deviation is sufficient for the Convention not entering into force. Consider now the same profile under Convention $R$. If a signatory country deviates from such a profile it will also lose $\alpha_{i}$ and will suffer a reduction in the benefits of procurement., so that the deviation payoff is the same as with $U(\tau)$. But because, when $\tau<N$, the enforcement costs under $R$ are smaller than under $U(\tau)$, the equilibrium payoff under $R$ is larger. This means that if a signatory country does not find it profitable to deviate from a profile with $\tau$ signatory country under $U(\tau)$, it will also find it profitable not to deviate under $R$. This implies that under $R$ there exists a SPNE with either $\tau$ or strictly more than $\tau$ signatory countries.

In the case of $n>\tau$ signatory countries the argument is reinforced by the fact that under $U(\tau)$ a unilateral deviation leaves the benefits of procurement to the deviator unaffected, whereas under $R$ a deviation for a signatory country leads to a reduction in the benefits of procurement and a deviation for a nonsignatory country leads to a gain in the benefits of procurement.

This shows that for $\tau<N$ and $n \geq \tau, \alpha \in \mathcal{A}(U(\tau), n)$ implies that $\alpha \in \mathcal{A}(R, n)$.

We now want to show that for $\tau<N$ and $n \geq \tau$, there exist an $\alpha \in \mathbb{R}^{N}$ such that $\alpha \notin$ $\mathcal{A}(U(\tau), n)$ and $\alpha \in \mathcal{A}(R, n)$.

Let $\alpha^{*} \in \mathbb{R}^{N}$ be such that country $\tau$ is exactly indifferent between deviating or not from a profile in which $\tau$ countries sign Convention $U(\tau)$ and such that the rest of the signatory countries strictly prefer to sign and nonsignatory countries prefer not to sign.

Consider now $\alpha^{* *} \in \mathbb{R}^{N}$ such that

$$
\begin{aligned}
& \alpha_{i}^{* *}=\alpha_{i}^{*}-\varepsilon \text { for } i=1, \ldots, \tau \\
& \alpha_{i}^{* *}=\alpha_{i}^{*}-\delta \text { for } i=\tau+1, \ldots, N
\end{aligned}
$$

Consider $\delta>0$ such that for all $\varepsilon \in(0, \delta), \alpha^{* *} \notin \mathcal{A}(U(\tau), \tau)$. Given that a signatory country's enforcement costs under $R$ are lower than under $U(\tau)$, a signatory country's deviation payoff is lower and this implies that there exist $\varepsilon \in(0, \delta)$ such that $\alpha^{* *} \in \mathcal{A}(R, \tau)$. In the case of $n>\tau$ signatory countries, the argument is reinforced by the fact that under $U(\tau)$ a unilateral deviation leaves the benefits of procurement to the deviator unaffected, whereas under $R$ a deviation for a signatory country leads to a reduction in the benefits of procurement and a deviation for a nonsignatory country leads to a gain in the benefits of procurement.

Part 2: Consider a profile in which all $N$ countries sign Convention $U(N)$ or Convention $R$, respectively. Notice that the payoffs associated with this profile in $\Gamma(\alpha, U(N))$ and $\Gamma(\alpha, R)$ are identical and so are the deviation payoffs. This implies that $\mathcal{A}(U(N), N)=\mathcal{A}(R, N)$.

\section{B An Alternative Model of Bribing}

The purpose of this appendix is to verify that the main properties of the model of bribing we have proposed hold under a different specification of the probability of a firm succeeding in bribing the public official of a given country. We consider a case in which the probability of winning the auction is increasing in its own bribe and increasing in the difference between its own bribe and the average bribe. This implies the probability of succeeding in bribing the public official is decreasing in the bribes bid by competing firms. This creates a strategic complementarity that implies that if a firm bids a higher bribe, all its opponents also find it optimal to bid higher bribes. We show 
that the properties of the bidding game that were established in Corollary 1 hold under this new specification and we therefore conclude that the analysis of international conventions would be qualitatively unchanged under this alternative specification.

Assume that each firm sets a nonnegative bribe and that the probability that a corrupt transaction takes place between firm $(i, j)$ (incorporated in country $i$ and operating in country $j$ ) and the public official of country $j$ is

$$
\gamma_{i j}=\frac{\beta_{i j}+l\left(\beta_{i j}-\frac{1}{N} \sum_{z=1}^{N} \beta_{z j}\right)}{B}
$$

with $\gamma_{i j} \in[0,1], B>0$, an exogenous parameter that measures public officials' propensity to corruption and $l \in[0,1)$. Notice that $\gamma_{i j}$ is increasing in $\beta_{i j}$ and decreasing in $B$ and $\beta_{z j}, z \neq i$. Firm $(i, j)$ is required to pay the bribe it offered, $\beta_{i j}$, only if it wins the auction. Under this probabilistic auction a firm that bids a higher bribe has a higher probability of corrupting the public official, but this probability is less than 1, and all firms $i$ that bid bribes

$$
\beta_{i j}>\frac{l}{N+l N-l} \sum_{z \neq i} \beta_{z j}
$$

have a strictly positive probability to succeed in bribing the public official. When all firms have a strictly positive probability of bribing the public official of the country in which they operate, the probability of corruption in country $j$ is

$$
\gamma_{j}=\sum_{i=1}^{N} \gamma_{i j}=\sum_{i=1}^{N} \frac{\beta_{i j}+l\left(\beta_{i j}-\frac{1}{N} \sum_{z=1}^{N} \beta_{z j}\right)}{B}=\frac{\sum_{i=1}^{N} \beta_{i j}}{B}
$$

In the following we will restrict attention to situations in which each firm has a strictly positive probability of bribing the public official of the country in which it operates and in which the probability of each public official being bribed is strictly less than 1, i.e., to cases in which, for all $j$

$$
\sum_{i=1}^{N} \beta_{i j}<B
$$

We now want to characterize the bribes in the equilibrium of the subgame that starts at the beginning of stage 3, i.e., after governments have set penalties and monitoring probabilities. In particular, we want to characterize how equilibrium bids and the resulting probabilities of corruption depend on monitoring probabilities and penalties. In other words, we want to perform the same comparative statics exercises that were performed in Corollary 1 and that lie at the heart of the results of the paper.

Firm $(i, j)$ 's maximization problem is

$$
\max _{\beta_{i j}} \frac{\beta_{i j}+l\left(\beta_{i j}-\frac{1}{N} \sum_{z=1}^{N} \beta_{z j}\right)}{B}\left[(\bar{K}-\underline{K})-\beta_{i j}-\mu_{j} \pi_{i j}\right] .
$$

Given that the model in the paper corresponds to the case in which $l=0$, in the following we will focus on the case $l \in(0,1)$. We find it convenient to divide the previous expression by $l$ and let $h=(1+l) / l$. Notice that $l \in(0,1)$ implies $h>2$. Firm $(i, j)$ 's maximization problem can then be rewritten as

$$
\max _{\beta_{i j}} \frac{h \beta_{i j}-\frac{\sum_{z=1}^{N} \beta_{z i}}{N}}{B}\left[(\bar{K}-K)-\beta_{i j}-\mu_{j} \pi_{i j}\right] .
$$


The solution of (19) is characterized by the first order condition

$$
\frac{2 h N-1}{N} \beta_{i j}=\frac{h N-1}{N}\left[(\bar{K}-\underline{K})-\mu_{j} \pi_{i j}\right]+\frac{\sum_{z=1}^{N} \beta_{z j}}{N} .
$$

Notice that because the first order condition is linear in the bribes, an equilibrium of the bribe setting game of stage 3 has to be symmetric, i.e., such that all firms that are penalized by their home country if found to have bribed the public official of country $j$, bid $\beta_{P j}$ and all remaining firms (who are not penalized) bid $\beta_{N P j}$. We denote by $n_{j}$ the number of countries that penalize their firms active in country $j$. We obtain

$$
\begin{aligned}
\beta_{P j} & =\frac{N}{2 N-1}\left[\frac{h N-1}{N}\left[(\bar{K}-\underline{K})-\mu_{j} \bar{\pi}\right]+\frac{\left(N-n_{j}\right) \beta_{N P j}+n_{j} \beta_{P j}}{N}\right], \\
\beta_{N P j} & =\frac{N}{2 h N-1}\left[\frac{h N-1}{N}[(\bar{K}-\underline{K})]+\frac{\left(N-n_{j}\right) \beta_{N P j}+n_{j} \beta_{P j}}{N}\right] .
\end{aligned}
$$

From (20) and (21) we obtain

$$
\begin{aligned}
\beta_{P j} & =\frac{h N-1}{(2 h-1) N-1}\left[(\bar{K}-\underline{K})-\frac{(2 h-1) N-1+n_{j}}{2 h N-1} \mu_{j} \bar{\pi}\right] \\
\beta_{N P j} & =\frac{h N-1}{(2 h-1) N-1}\left[(\bar{K}-\underline{K})-\frac{n_{j}}{2 h N-1} \mu_{j} \bar{\pi}\right]
\end{aligned}
$$

From (22) and (23) one can see that the equilibrium bribes are decreasing in $\mu_{j}, \bar{\pi}$ and $n_{j}$. From (22) and (23) we can also compute the expected corruption of individual firms when they are penalized for corruption, $\gamma_{P j}\left(\mu_{j}, n_{j}\right)$, and when they are not, $\gamma_{N P j}\left(\mu_{j}, n_{j}\right)$. Straightforward calculations show that

$$
\begin{aligned}
\gamma_{P j}\left(\mu_{j}, n_{j}\right) & =\frac{\frac{(h-1)(h N-1)}{(2 h-1) N-1}(\bar{K}-\underline{K})-\frac{h(h N-1)}{2 h N-1} \mu_{j} \bar{\pi}+\frac{h N-1}{((2 h-1) N-1) N} \frac{h N-1}{2 h N-1} n_{j} \mu_{j} \bar{\pi}}{B} \\
\gamma_{N P j}\left(\mu_{j}, n_{j}\right) & =\frac{\frac{(h-1)(h N-1)}{(2 h-1) N-1}\left[(\bar{K}-K)-\frac{n_{j}}{2 h N-1} \mu_{j} \bar{\pi}\right]+\frac{n_{j}}{N} \frac{h N-1}{2 h N-1} \mu_{j} \bar{\pi}}{B}
\end{aligned}
$$

Notice that

$$
\gamma_{P i}\left(\mu_{j}, n_{j}\right)<\gamma_{N P i}\left(\mu_{j}, n_{j}\right)
$$

and that $\gamma_{P j}\left(\mu_{j}, n_{j}\right)$ is increasing in $n_{j}$. The probability of corruption in country $j$ can then shown to be equal to

$$
\gamma_{j}\left(\mu_{j}, n_{j}\right)=\frac{\frac{(h-1) N(h N-1)}{(2 h-1) N-1}(\bar{K}-\underline{K})-\frac{(h-1)(2 h N-1)}{(2 h-1) N-1} \frac{h N-1}{2 h N-1} n_{j} \mu_{j} \bar{\pi}}{B}
$$

and is therefore decreasing in $n_{j}$.

We now want to analyze when an increase in $n_{j}$ causes the government of country $j$ to increase its monitoring intensity. In other words we want to verify under what conditions

$$
\frac{\partial \mu_{j}}{\partial n_{j}}>0
$$

in a subgame of $\Gamma$ starting at stage 2 . In particular we want to investigate how monitoring probabilities depend on $n_{j}$. Notice that because the monitoring probability set by country $j$ in 
stage 2 is independent of the probabilities set by the other countries, each government has a dominant strategy in stage 2. We make use of the following result of Edlin and Shannon (1998), ${ }^{18}$ which allows us to obtain strictly monotonic comparative statics results for interior solutions without making further assumptions on the concavity of problem.

Theorem 8 (Edlin and Shannon, 1998) Let $S \subset \Re, f: \Re \times \Re \rightarrow \Re, y^{*} \in \operatorname{argmax}_{y \in S} f\left(y, t^{*}\right)$ and $y^{\prime} \in \operatorname{argmax}_{y \in S} f\left(y, t^{\prime}\right)$. Suppose that $f$ is $C^{1}$ and has increasing marginal returns, and that $y^{*} \in$ int $S$. Then $y^{\prime}>y^{*}$ if $t^{\prime}>t^{*}$, and $y^{\prime}<y^{*}$ if $t^{\prime}<t^{*}$.

The problem that characterizes the stage 2 best response of the government of country $j$ can be written as

$$
\max _{\mu_{j}}(\bar{V}-\bar{K})-\gamma_{j}\left(\mu_{j}, n_{j}\right)(\bar{V}-\underline{V})-\frac{M}{2} \mu_{j}^{2}-\gamma_{j j}\left(\mu_{j}, n_{j}\right) \mu_{j} \frac{\pi_{j j}}{\bar{\pi}} P-\sum_{z \neq j} \gamma_{j z}\left(\mu_{z}, n_{z}\right) \mu_{z} \frac{\pi_{j z}}{\bar{\pi}} P .
$$

Let

$$
f\left(\mu_{j}, n_{j}\right)=-\gamma_{j}\left(\mu_{j}, n_{j}\right)(\bar{V}-\underline{V})-\frac{M}{2} \mu_{j}^{2}-\gamma_{j j}\left(\mu_{j}, n_{j}\right) \mu_{j} P+D
$$

where $D$ is a constant. Given that $f\left(\mu_{j}, n_{j}\right)$ is $C^{1}$ we only need to verify that $f\left(\mu_{j}, n_{j}\right)$ has increasing marginal returns, i.e., that $\partial f / \partial \mu_{j}$ is increasing in $n_{j}$.

Differentiating $f\left(\mu_{j}, n_{j}\right)$ with respect to $\mu_{j}$ we obtain

$$
\frac{\partial f}{\partial \mu_{j}}=-\gamma_{j}^{\prime}\left(\mu_{j}, n_{j}\right)(\bar{V}-\underline{V})-M \mu_{j}-\gamma_{j j}^{\prime}\left(\mu_{j}, n_{j}\right) \mu_{j} P-\gamma_{j j}\left(\mu_{j}, n_{j}\right) P
$$

where

$$
\begin{aligned}
-\gamma_{j}^{\prime}\left(\mu_{j}, n_{j}\right) & =(h-1) \frac{2 h N-1}{(2 h-1) N-1} \frac{h N-1}{2 h N-1} \frac{n_{j} \bar{\pi}}{B}(\bar{V}-\underline{V}), \\
-\gamma_{j j}^{\prime}\left(\mu_{j}, n_{j}\right) & =-\gamma_{P j}^{\prime}\left(\mu_{j}, n_{j}\right)=\left[-\frac{h(h N-1)}{2 h N-1}+\frac{h N-1}{((2 h-1) N-1) N} \frac{h N-1}{2 h N-1} n_{j}\right] \frac{\bar{\pi}}{B} .
\end{aligned}
$$

Differentiating $\partial f / \partial \mu_{j}$ with respect to $n$, we obtain

$$
\frac{\partial}{\partial n}\left(\frac{\partial f}{\partial \mu_{j}}\right)=\frac{(h N-1) \bar{\pi}}{((2 h-1) N-1) B}\left[(h-1)(\bar{V}-\underline{V})-\frac{h N-1}{2 h N-1} \frac{2 \mu_{j} P}{N}\right] .
$$

Given that

$$
\frac{(h N-1) \bar{\pi}}{((2 h-1) N-1) B}>0
$$

$\partial f / \partial \mu_{j}$ is increasing in $n_{j}$ if

$$
(h-1)(\bar{V}-\underline{V})-\frac{h N-1}{2 h N-1} \frac{2 \mu_{j} P}{N}>0
$$

or

$$
\frac{N(h-1)}{2} \frac{2 h N-1}{h N-1}>\frac{\mu_{j} P}{\bar{V}-\underline{V}}
$$

\footnotetext{
${ }^{18}$ Edlin, A. and C. Shannon (1998) "Strict Monotonicity in Comparative Statics," Journal of Economic Theory, Vol. 81, pp. 201-219.
} 
In other words, when condition (26) holds, from Theorem $8, \mu_{j}$, the monitoring probability set by country $j$ in stage 2 is increasing in $n_{j}$, the number of countries which in stage 1 set a penalty for their firm active in country $j$. Recalling that

$$
\begin{aligned}
\overline{\bar{V}-\underline{V}} \overline{\bar{K}}-\underline{K} & >P \\
(\bar{K}-\underline{K})-\mu_{j} \bar{\pi} & >0
\end{aligned}
$$

we can conclude that

$$
\frac{\mu_{j} P}{\bar{V}-\underline{V}}<1
$$

This implies that a sufficient condition for (26) to hold is that

$$
\frac{N(h-1)}{2} \frac{2 h N-1}{h N-1}>1
$$

which can be verified to hold for $h>2$.

From (27) it is easy to recognize that corruption in country $j$ is decreasing in $n_{j}$,

$$
\frac{d \gamma_{j}\left(\mu_{j}, n_{j}\right)}{d n_{j}}=\frac{\partial \gamma_{j}\left(\mu_{j}, n_{j}\right)}{\partial n_{j}}+\frac{\partial \gamma_{j}\left(\mu_{j}, n_{j}\right)}{\partial \mu_{j}} \frac{\partial \mu_{j}}{\partial n_{j}}<0
$$

It is also possible to show that when $n_{j}$ increases the equilibrium utility of country $j$ increases. To see this, it is sufficient to show that country $j$ 's utility increases even if it does not modify $\mu_{j}$, or, equivalently, that $f$ is increasing in $n_{j}$. Straightforward calculations show that this holds whenever

$$
\frac{(h-1)(h N-1) \mu}{(2 h-1) N-1} \frac{\bar{\pi}}{B}(\bar{V}-\underline{V})-\frac{h N-1}{(2 h-1) N-1} \frac{h N-1}{2 h N-1} \frac{\bar{\pi} \mu^{2} P}{B N}>0
$$

and that (27) implies (28). 


\section{REFERENCES}

[1] Burns, J. (2002) "Laws fail to halt international business bribery", Financial Times, October 15,2002 , page 12 .

[2] Celentani, M. and J.-J. Ganuza (2002) "Corruption and competition in procurement", European Economic Review, 46, 1273-1303.

[3] Davis, K.E. (2002) "Self-interest and altruism in the deterrence of transnational bribery," American Law and Economics Review, 4(2), 314-340.

[4] Eigen, P. (2002) "Multinationals' bribery goes unpunished", International Herald Tribune, November 12, 2002, page 6

[5] Laffont, J.-J. and T. N'Guessan (1999) "Competition and corruption in an agency relationship" Journal of Development Economics 60, 271-295.

[6] Laffont, J.-J. and J. Tirole (1991) "Auction design and favoritism" International Journal of Industrial Organization 9, 9-42.

[7] The Economist (2002) "The short arm of the law", March 2, 2002, 63-65. 